Document downloaded from:

http://hdl.handle.net/10251/170076

This paper must be cited as:

Salas, JD.; Anderson, ML.; Papalexiou, SM.; Francés, F. (2020). PMP and Climate Variability and Change: A Review. Journal of Hydrologic Engineering. 25(12):1-16. https://doi.org/10.1061/(ASCE)HE.1943-5584.0002003

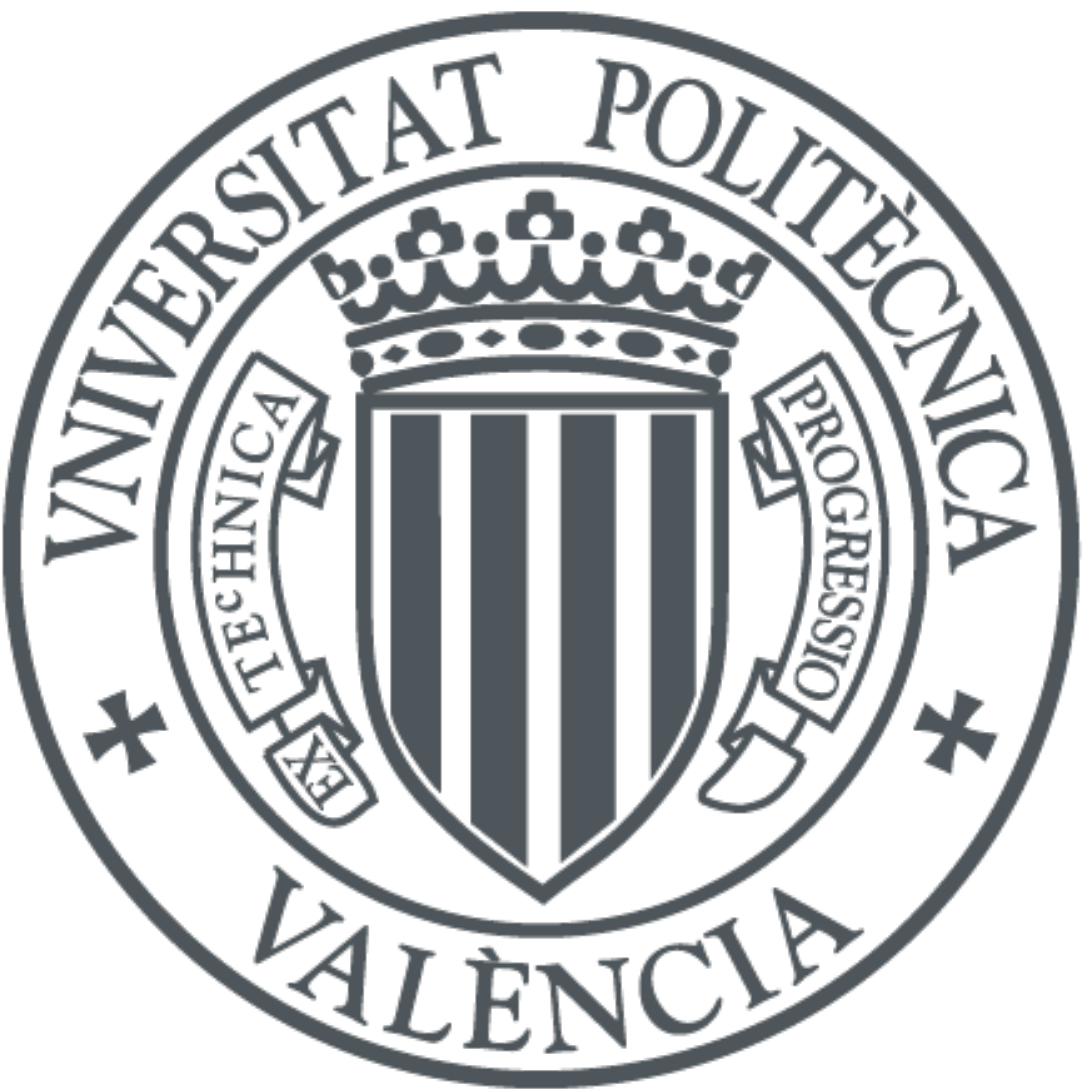

The final publication is available at

https://doi.org/10.1061/(ASCE)HE.1943-5584.0002003

Copyright American Society of Civil Engineers

Additional Information 


\title{
PMP and Climate Variability and Change
}

\author{
Jose D. Salas ${ }^{1}$, Michael L. Anderson ${ }^{2}$, Simon M. Papalexiou ${ }^{3,4}$, and Felix Frances ${ }^{5}$
}

\begin{abstract}
A state-of-the-art review on the Probable Maximum Precipitation (PMP) as it relates to climate variability and change is presented. The review consists of an examination of the current practice and the various developments published in literature. The focus is on relevant research where the effect of climate dynamics on the PMP are discussed as well as statistical methods developed for estimating very large extreme precipitation including the PMP. Often confusion arises on the interpretation of extreme events without considering the effect of low frequency components of the climate system, their probabilistic nature that may be described by heavy-tail models, and the effect of the uncertainty of several factors determining them, such as atmospheric moisture, its transport into storms, wind, and their future changes. The review examines these issues as well as the underlying historical and proxy data. In addition, we summarize the procedures and guidelines established by some countries (e.g. USA, Australia, Canada, UK, EU, and others), states (e.g. California, Quebec), and the current manual of the World Meteorological Organization for estimating the PMP. In doing so, we paid attention whether the current guidelines and research published literature take into consideration the effects of the variability and change of climatic processes and the underlying uncertainties.
\end{abstract}

1 Professor Emeritus, Department of civil and Environmental Engineering, Colorado State University, Fort Collins, Colorado. Email: jose.salas@colostate.edu

${ }^{2}$ State Climatologist, California Department of Water Resources, Sacramento, California. Email: Michael.L.Anderson@water.ca.gov

${ }^{3}$ Assistant Professor, Department of Civil, Geological and Environmental Engineering, University of Saskatchewan, Canada; ${ }^{4}$ Global Institute for Water Security, Saskatchewan, Canada. Email: sm.papalexiou@usask.ca

${ }^{5}$ Professor of Hydrology, Research Institute of Water and Environmental Engineering (IIAMA), Universitat Politècnica de València, Spain. Email: $\underline{\text { ffrances@upv.es }}$ 


\section{Introduction}

The evaluation and design of some hydraulic structures such as spillways, flood defenses, and protection of nuclear power plants, whose failure may cause the loss of human lives and significant damages to property and the environment are generally based on extreme events of precipitation and flow that have very small likelihood of occurrence. Before the 1950's concepts and methods were developed such as the maximum possible precipitation (MPP), which gave the impression that such quantity (and correspondingly the ensuing flood), would never be exceeded and consequently the structures designed based on them would have zero risk of failure. However, as additional data of extreme occurrences were collected, it became clear that modifications needed to be made and eventually the MPP was abandoned and replaced by the probable maximum precipitation (PMP) and the corresponding probable maximum flood (PMF), which should be understood as being quantities with very small chance of being exceeded. Thus, the PMP definition which has been widely accepted in literature is: "theoretically the greatest depth of precipitation for a given (storm) duration that is physically (meteorologically) possible over a given size storm area at a particular geographical location at a certain time of the year" (WMO 1986, 2009). The referred definition and PMP estimates have "no allowance made for long-term climatic trends".

PMP is a theoretical concept but can be estimated. It is one of the inputs used to determine the PMF. Thus, various methods have been developed to determine the PMP and PMF. In this review we focus on methods related to the PMP. They are generally described in some detail in the World Meteorological Organization (WMO) manuals (e.g. WMO 2009), which include: (1) the local method (local storm maximization model), (2) the transposition method (storm transposition model), (3) the combination method (temporal and spatial maximization of storm), (4) the inferential method (theoretical model), (5) the generalized method, and (6) the statistical method. The first five are based on physical hydrometeorological laws while the last one is based on 
statistical laws. In addition, the referred WMO manual includes applications for some countries such as US, Canada, China, Australia, India, and basins located in orographic and tropical regions. Furthermore, several countries developed their own manuals for estimating PMP and PMF even though the referred WMO manual has been the primary guide. And in some cases, updates have been made as more data became available, more applications and experience gained, and the estimation methods improved. The referred hydrometeorological and statistical methods are further reviewed in the following sections considering climate variability and change and the sources and methods to account for uncertainties.

Since the last decades of the $20^{\text {th }}$ Century advances have been made on our understanding of the dynamics of the climate system, its natural variability, and the occurrence and effects of large scale low and high frequency phenomena such as ENSO, PDO, AMO, NAO, and others. Depending on the location of the earth, the effect of these systems on extreme precipitation can be substantial. In some cases, precipitation data of a given region may be available during say a 30yr period coinciding with a cold state of the $\mathrm{AMO}$, and consequently the precipitation extremes and PMP estimates based on data during such period would be bias downward. Furthermore, it also has become clear the effect of human interference on the environment and on the climate system, enhancing its natural variability (e.g. global warming) and causing changes on hydrometeorological processes and the various components of the hydrological cycle thereby intensifying extreme events.

The main objective of this paper has been to review literature on the various methods for estimating the PMP and focus on what is being done to consider the effect of climate variability and change on extreme events such as the PMP. The occurrence of such large extreme events is a complex process and consequently the methods developed to estimate them involve several 
sources of uncertainties. The Hydrometeorological and Statistical methods that are available for estimating the PMP are reviewed in the following two sections. The Statistical Methods section includes two subsections, namely, the Traditional Statistical Method (due to Hershfield) and Statistical Alternatives. In the referred sections and subsections, the extensions, improvements, applications, and the studies made for considering the effects of climate variability and change and accounting for uncertainties are included. Next is a section summarizing the guidelines and studies available in some countries. The final section includes some comments and remarks.

\section{PMP Based on Hydrometeorological Methods}

A number of methods exist to quantify the PMP. The origins of these methods often start with observed extreme precipitation events and explore the meteorological conditions surrounding the event. Precipitation processes related to PMP estimates in the United States (US) are described in the US Weather Bureau's Technical Paper 38, hereafter referred as TP38, (Weather Bureau 1960) including atmospheric moisture, dewpoint temperature, lifting and cooling processes, horizontal convergence, and orographic processes. Guidelines for PMP estimation are provided by the US Weather Bureau and subsequently by the US National Weather Service in its hydrometerological report (HMR) series. Tomlinson and Kappel (2009) provide an overview of the development of the HMR series. A graphic showing the latest reports and their regional coverage for the US is shown in Fig.1. Note the regionalization of the reports and the specialized storm spatial extents for the mountainous areas in western North Carolina and neighboring states.

In HMR 36 (US Weather Bureau 1969), the guidelines for probable maximum precipitation computations are presented for California. In a companion volume, HMR 37 (Weaver 1962), the meteorology of major flood producing storms are discussed noting different characteristics of storms that produce extreme precipitation for California and the west coast of the United States. 
HMR 36 was later updated to HMR 58 for PMP computations and a companion volume HMR 59 for probable maximum flood computations. The HMR guidelines discuss both large-scale frontaltype storms as well as more localized downpours from convective events. Guidance is provided to scale the precipitation for area to create a basin-average precipitation depth for a given basin area over a given time period ranging from 1 to 72 hours. East of the Continental Divide, precipitation extremes are associated with convective events of anomalous strength or duration. These convective events can arise from landfalling tropical systems like hurricanes or from summer convective activity that does not move off from a given location. Figure 1 shows the HMR documents that treat the estimation of these types of extremes.

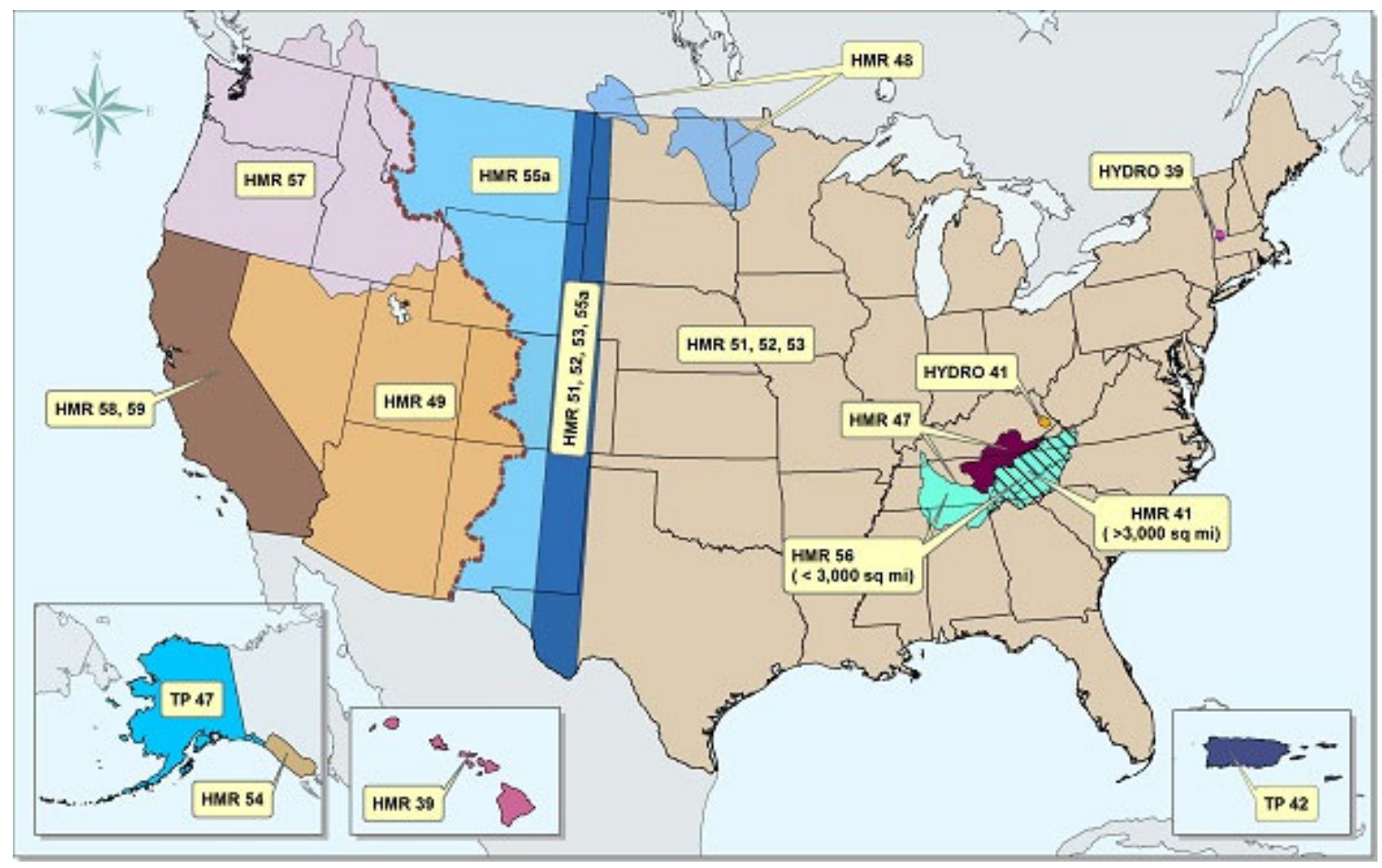

Fig. 1. Map of the US indicating the various regions and states where the HMRs apply for estimation of PMP and PMF (source: (https://www.nws.noaa.gov/oh/hdsc/studies/pmp.html)) 
A common approach for exploring PMP estimates is working from an observed extreme. The characteristics of that extreme event like those described in TP38 are explored for limiting conditions to the amount of precipitation. Explorations can be made to determine if relaxing those limiting conditions results in a higher amount of precipitation. To expand the population of extreme events, some studies have looked at transposing nearby storms over the desired study location. Such transpositions should be examined for meteorological consistency for consideration in the expanded population. Extrapolation of individual variables for maximizing possible precipitation can be difficult given the nonlinear nature of atmospheric processes and their interactions in precipitation generation.

An alternative approach to represent the nonlinear processes governing storm formation and associated precipitation processes is the use of atmospheric models. The scale of the simulation matters both for convective versus larger-scale, frontal storm structures. Interaction with topography through orographic processes is also important to simulate. Precipitation parameterization and cloud physics parameterization choices are also important. Abbs (1999) used a numerical model of the atmosphere to evaluate assumptions used in PMP analyses. Parzybok and Tomlinson (2006) explore the use of Geographic Information Systems and radar data in sitespecific analyses of PMP. Ohara et al. (2011) describe a method for maximizing precipitation over a select watershed in California. In more location-specific analyses, Ishida et al. (2014) used a method called boundary condition shifting to realign a number of California's historical extreme storms to pass over selected watersheds. In a companion paper (Ishida et al. 2015), the authors relaxed the atmospheric moisture boundary condition to maximize the amount of moisture entering the region to evaluate the increase in precipitation. And in a third study Ishida et al. (2016) evaluated the impact of air temperature and moisture holding capacity on probable maximum 
precipitation. Further work on modeling PMP in California was accomplished by Diaz et al. (2017), Toride et al. (2017), and Ohara et al. (2017).

As the atmosphere continues to warm in the $21^{\text {st }}$ Century, it will be important to better understand increases in atmospheric temperature and associated changes in ocean temperatures and heat content, and changes on the land surface all interact to drive extreme precipitation formation. Efforts like Dettinger (2011) exploring processes associated with atmospheric rivers in GCMs to evaluate potential future extreme precipitation offer insights into what may happen with PMPs. Kunkel et al. (2013) explored expected changes in atmospheric moisture content and changes in winds associated with climate change could impact estimates of the PMP. They found that moisture content changes have a larger impact than expected changes in wind fields. Toride et al. (2018) explored long term trends in extreme precipitation in watersheds feeding into Shasta Dam in Northern California. Recent extremes like super-storm Sandy or Hurricane Harvey have pushed the boundaries of historical estimates of PMP and suggested that further work on these types of events in a warmer world are warranted (e.g. Kao et al. 2019). Villarini et al. (2013) examine historical precipitation observations to identify increasing frequencies of heavy precipitation in the northern part of the Central United States and points to the increasing temperatures and associated water vapor transport as possible causes. Rastogi et al. (2017) used a numerical model to explore potential impacts to PMP estimates due to a warming atmosphere for a region in the southeast United States. Their results suggest further study of how increasing extremes with warming temperatures can influence the PMP. Mahoney et al. (2018) explore climate change and PMP estimates for dam safety for Colorado and New Mexico.

Even though the PMP estimation based on hydrometeorological methods has become the preferred method because it involves the underlying dynamic and thermodynamic processes, 
however it is quite complex and despite the advances made in numerical and computational algorithms and data collection techniques, still includes a large number of uncertainties. Micovic et al. (2015) discuss in some detail the factors that influence the PMP estimation such as moisture maximization, storm separation method, temporal and spatial characteristics, and historical storm data. In addition, they point out that climate change will likely change moisture maximum, storm efficiencies, precipitation intensities, wind speeds, and freezing levels. Also as mentioned above, the simulation studies by Kunkel et al. (2013) based on several climate models indicate approximately $20-30 \%$ increase in maximum water vapor concentrations, one of the key inputs in PMP estimation. Thus Kunkel et al. concluded that PMP values will increase in the future due to higher levels of atmospheric moisture content and higher levels of moisture transport into storms.

Micovic et al. (2015) considering the PMP estimates for La Joie basin in Canada, proposed a method for assessing PMP uncertainty by identifying the uncertain parameters, determining the plausible range of parameter values, and characterize the distribution of the range of values of each parameter. They applied Monte Carlo simulation to determine the sensitivity of the 24-hr PMP and the empirical distribution of the PMP estimates. The method included the contribution from five sources of uncertainty. The results suggest the PMP estimate to be the most sensitive to the factors related to storm efficiencies and in-place moisture maximization. And the resulting distribution give empirical quantiles (e.g. the 90\%) of the PMP. Further details for their method and results including the uncertainty bounds for the 48-hr and 72-hr PMPs can be found in the reference above.

\section{PMP Based on Statistical Methods}

\section{Traditional Statistical Method}

The statistical method commonly utilized in practice, particularly for basins lacking hydrometeorological data, has been originally proposed by Hershfield $(1961,1965,1977)$ and 
popularized internationally by WMO $(1973,1986,2009)$. Hershfield's statistical method is based on Chow's frequency equation where a quantile of the underlying distribution is expressed as a function of the sample mean, the sample standard deviation, and a frequency factor $K$ (e.g. Chow 1951; Chow et al. 1988). In the typical procedure for fitting the empirical frequency distribution of the data at hand using a probability distribution function, there is a one-to-one correspondence between a quantile and the value of $K$. However, in Hershfield's application of the frequency equation the value of $K$ (denoted as $K_{m}$ ) was established after analyzing a large number of historical data of extreme storms of annual daily maximums so that an upper bound of $K$ was determined, which was bigger than all values of $K$ obtained from the historical sample. Hershfield realized that since the PMP estimated from such an equation (Eq. 1a below) was a function of the mean, the standard deviation, and the factor $K_{m}$, which were quantities obtained from a limited historical sample, he developed a procedure for adjusting them to account for the sample size and additional improvements as indicated below.

Hershfield (1961) method was developed based on 24-hour annual maximum precipitation data collected worldwide at 2,645 stations ( $90 \%$ of which were stations located in the United States and the rest of them from other parts of the world), which gave a total of about 95,000 stationyears data. The method was based on the equation

$$
P M P=\bar{X}_{n}+K_{m} S_{n}
$$

where $\bar{X}_{n}$ is the mean annual maximum daily precipitation, $S_{n}$ is the corresponding standard deviation, and $K_{m}$ is the factor suggested by Hershfield. As indicated above, Hershfield suggested adjusting $\bar{X}_{n}$ and $S_{n}$ for sample size and for the effect of outliers. For this purpose, Hershfield (1961) provided graphs from which one can obtain the appropriate adjustment factors. These graphs are also available in the WMO manuals (e.g. WMO, 2009). Another correction suggested 
by Hershfield was to account for the difference that exists between the daily maximum values and the 24-hour maximums regardless of the calendar day.

Based on the extreme precipitation data of the 2,645 stations, Hershfield (1961) found that the value of $K_{m}$ in Eq.(1a) varied in the range 1.00 - 14.99 and that $K_{m}$ ranged between 13.00 and 14.49 for only 4 stations. Consequently, Hershfield suggested utilizing the value of $K_{m}=15$ for estimating the PMP. However, additional studies by Hershfield $(1965,1977)$ indicated that $K_{m}$ varied with the storm duration and the mean annual maximum precipitation, therefore he provided additional relations for determining the value of $K_{m}$ for practical applications. For example, for a 24-hr PMP Hershfield (1977) gave $K_{m}(24)=19(10)^{-0.000965 \bar{X}_{n}(24)}$ in which $K_{m}(24)$ is the factor $K_{m}$ for 24-hr storm duration and $\bar{X}_{n}(24)$ is the 24-hr mean annual maximum precipitation.

Furthermore, other studies appeared in literature applying and modifying Hershfield's method and documenting the most appropriate values of $K_{m}$ according to the climatic region of the study areas. For example, Mejía and Villegas (1979) suggested the envelopes for determining $K_{m}$ as a function of the mean annual maximum precipitation for Colombia. And similar studies can be found for other locations of the world such as, the southern half of the Indian Peninsula (Dhar et al. 1980), the Alpine Region in Austria (Nobilis et al. 1990), the Indian Peninsula or estimating the 2-day duration PMP (Rakhecha et al. 1992), the North Region of India (Rakhecha and Soman 1994), the Czech Republic (Rezacova et al. 2005), the South Region of Malaysia (Desa and Rakhecha 2007), and the Cataluña Region of Spain (Casas et al. 2008). In addition, Lin and Vogel (1992) rederived the expression of the factor $K_{m}$ and provided some criteria for its application. Casas et al (2016) using a large data base of storm rainfall for the Iberian Peninsula, applied Hershfield's method to estimate PMP for 24-hr rainfall duration based on the factor $K_{m}$ determined as a function of $\bar{X}_{n}$ (24). And based on scaling concepts determined the PMP for sub-daily (hourly) 
durations. Lan et al (2017) indicated that using a standardized factor denoted by $\Phi$ is more appropriate for estimating PMP than using $K_{m}$ for China, although other studies (e.g. Lin and Vogel, 1993) indicated the opposite. They provided relations between $\Phi$ and $K_{m}$ and comparisons based on data from Hong Kong.

Hershfield (1961) recognized the fact that $K_{m}$ in Eq.(1a) is a random variable and illustrated this point by associating the values of $K_{m}$ with the return period using as examples the Gumbel and Lognormal distributions. His rationale was finding a value (an envelope function) that could be applicable for a given storm duration and climatic region. Such an envelope was obtained based on a large data base of numerous storms that have been observed in historical records at similar locations. In finding the envelope for $K_{H}$, Hershfield (1965, p. 967) argued that "enveloping $K_{m}$ as a function of the mean serves a transposition purpose."

On the other hand, Koutsoyiannis (1999) suggested fitting the general extreme value (GEV) distribution function to Hershfield's data because it deals with extreme precipitation events. Thus, after carefully re-examining Hershfield's results Koutsoyiannis concluded that the $K_{m}=15$ suggested by Hershfield corresponds approximately to a return period of 60,000 years based on the GEV distribution. Koutsoyiannis also illustrated his alternative approach using 136 years of data of annual maximum daily rainfall in Greece. As expected, such a long record offers the alternative of fitting the frequency distribution of the data and finding quantiles for any desired return period. Likewise, Papalexiou and Koutsoyiannis (2006) argued that the estimates of the PMP based on maximization of storm moisture do not appear having an upper bound. Their analysis of dewpoint temperature, atmospheric moisture, and maximized precipitation showed that no upper bounds were evident. Therefore, they suggested finding design values of maximum precipitation using the frequency analysis of the observed data based on the GEV distribution. Douglas and Barros (2003) approached the design of maximum precipitation using a completely 
different method, which is based on applying multifractal concepts for determining what they called the fractal maximum precipitation (FMP) and applied their approach to the eastern United States.

When using short records, there is a lack of information on large hydrological events, which is one of main drawbacks in flood frequency analysis (Merz and Bloschl 2008). In other words, there is a need of "temporal information expansion" as indicated by Merz and Bloschl to obtain results concerning quantiles of large return periods reliable enough. For this reason, several studies of high return period extreme floods based on historical and paleo-hydrologic data have been proposed (e.g. Stedinger and Cohn 1986; Frances et al. 1994; Frances, 1997; England et al. 2004) and Botero and Frances (2010) applied them for PMF analysis. While these techniques have been developed mostly for frequency studies of extreme flood data, they are briefly mentioned in this review because of the obvious relation of the PMP and PMF. A more in-depth review of the various alternative statistical methods is included in the following section.

Despite that the traditional statistical method by Hershfield (1961) was developed over 50 years ago and the many advances made on hydrometeorological based methods, Hershfield's method with modifications or not continues to be widely utilized in practice in many countries particularly in locations lacking hydrometeorological data as indicated by many papers published in the last few years such as Japan (Alias et al. 2013), India (Chavan and Srinivas 2017), and Thailand (Wangwongwiroj and Khemngoen 2019). Nevertheless, the practice of designing and evaluating flood related structures based on such PMP (and the ensuing PMF) have been criticized among others because of the many uncertainties involved in determining them (e.g. Dawdy and Lettenmaier 1987.) The tendency in the last two decades has been modifying the traditional statistical approach to include uncertainty and risk analysis in the estimation and selection of the PMP for project design or evaluation. They are discussed in the reminder of this section. 
Furthermore, statistical alternatives based on fitting probability distribution functions as suggested by Koutsoyiannis (1999) and many others, are discussed in the following section.

Several studies have recognized that the estimation of the PMP using hydrometeorological and statistical methods involve many uncertainties (e.g. Mamoon and Rahman 2014; Salas et al. 2014; Micovic et al. 2015; Singh et al. 2018). Regarding Hershfield's traditional statistical PMP estimation, Salas et al (2014) proposed a simple method to consider the uncertainty of the PMP arising from the uncertainty of the sample mean $\bar{X}_{n}$ and the sample standard deviation $S_{n}$. Referring to the original equation (1a) used by Hershfield (1961), one may observe that the PMP is a function of the sample mean $\bar{X}_{n}$, the standard deviation $S_{n}$, and the coefficient $K_{m}$. Since the sample statistics are random variables, then the PMP is an estimator that can be denoted as $\hat{P}$ and Eq.(1a) is rewritten as

$$
\hat{P}=\bar{X}_{n}+K_{m} S_{n}
$$

where $n$ represents the sample size (number of years of data). Also let us recall that

$$
\bar{X}_{n}=\frac{1}{n} \sum_{i=1}^{n} X_{i} \quad \text { and } \quad S_{n}=\sqrt{[1 /(n-1)] \sum_{1}^{n}\left(X_{i}-\bar{X}_{n}\right)^{2}}
$$

where $X_{1}, X_{2}, \ldots, X_{n}$ is a random sample from an unknown distribution with population mean $\mu$ and variance $\sigma^{2}$. Because $\bar{X}_{n}$ and $S_{n}$ are uncertain quantities and considering $K_{m}$ as a constant (i.e. a maximum value for the region where the basin of interest is located), Salas et al. (2014) determined the mean and the variance of the PMP estimator $\hat{P}$. It may be worth mentioning that using a constant value of $K$ follows Hershfield's approach in which $K$ was established after analyzing data of historical storms that have occurred in the regions of study. Thus, the uncertainty 
associated with $K$ is accounted for by using an envelope function and as such $K$ is a constant, and the remaining uncertainty is associated with $\bar{X}_{n}$ and $S_{n}$.

Therefore, it may be shown that the expected value of the estimator $\hat{P}$ is (Salas et al. 2014)

$$
E(\hat{P})=\mu+K_{m} \frac{\Gamma(n / 2)}{\sqrt{(n-1) / 2} \Gamma[(n-1) / 2]} \sigma
$$

where $\mu$ and $\sigma$ represent the mean and the standard deviation of the population, respectively and $\Gamma(a)$ represents the incomplete gamma function with argument $a$. Note that in estimating $E(\hat{P})$ for an actual case the population quantities $\mu$ and $\sigma$ are replaced by their corresponding sample estimates (after the appropriate adjustments for outliers as needed as suggested by Hershfield.) Likewise, the standard deviation of the estimator $\hat{P}$ of Eq. (1b) can be calculated as

$$
\sigma(\hat{P})=\left[\operatorname{Var}\left(\bar{X}_{n}\right)+K_{m}^{2} \operatorname{Var}\left(S_{n}\right)+2 K_{m} \operatorname{Cov}\left(\bar{X}_{n}, S_{n}\right)\right]^{1 / 2}
$$

where $\operatorname{Var}\left(\bar{X}_{n}\right)=\sigma^{2} / n$. The terms $\operatorname{Var}\left(S_{n}\right)$ and $\operatorname{Cov}\left(\bar{X}_{n}, S_{n}\right)$ depend on the parent distribution. For example, the normal approximations for determining $\operatorname{Var}\left(S_{n}\right)$ and $\operatorname{Cov}\left(\bar{X}_{n}, S_{n}\right)$ are $\operatorname{Var}\left(S_{n}\right) \approx \sigma^{2} / 2(n-1)$ and $\operatorname{Cov}\left(\bar{X}_{n}, S_{n}\right) \cong 0$ (Kendall and Stuart 1963). In general, for any distribution, it may be shown that the standard deviation $\sigma(\hat{P})$ of Eq.(3a) can be written as

$$
\sigma(\hat{P}) \cong \frac{\sigma}{\sqrt{n}} \sqrt{1+\left[\frac{n K_{m}^{2} f}{2(n-1)}\right]+\left[\frac{n K_{m}^{2} f}{2(n-1)}\right]^{1 / 2} \times \rho\left(\bar{X}_{n}, S_{n}\right)}
$$

where $f$ is an adjustment factor defined as $f=\operatorname{Var}\left(S_{n}\right) /\left[\sigma^{2} / 2(n-1)\right]$ and $\rho\left(\bar{X}_{n}, S_{n}\right)$ is the correlation coefficient. Note that for the normal distribution $f=1$ and $\rho\left(\bar{X}_{n}, S_{n}\right)=0$. Simple tables and graphs are available for determining $f$ and $\rho\left(\bar{X}_{n}, S_{n}\right)$ assuming the Gumbel (Salas et al. 2014) and log-Gumbel (Salas and Salas, 2016) distributions. And applications can be found in the given references. 
In addition, Singh et al (2018b) studied the uncertainty of the PMP estimates when using envelope curves of the frequency factor $K_{m}$, the number of stations used for constructing them, and suggested that basin specific curve should be used rather than Hershfield's curve. Likewise, the return period of the PMP was determined by fitting a wide range of probability distribution functions such as the GEV, log-logistic, log-Pearson 3, and BurrXII for the Brazos River in Texas, and concluded that the BurrXII was the best distribution for the referred data. Furthermore, Singh et al. (2018a) considered the relative contribution of the uncertainties of $\bar{X}_{n}, S_{n}$, and $K$, on the uncertainty of $\hat{P}$ and concluded that the uncertainty due to $\bar{X}_{n}$ is more important than the other two.

Considering the uncertainty of the mean $\bar{X}_{n}$ and the standard deviation $S_{n}$ and the ensuing uncertainty of the PMP estimator $\hat{P}$, Salas et al. (2014) suggested that one can estimate design values of the PMP as

$$
\hat{P}_{d}=E(\hat{P}) \pm c \sigma(\hat{P})
$$

where $\hat{P}_{d}$ represents a design PMP value and $c>1$. Note that $\hat{P}_{d}$ is a quantile of the uncertain quantity $\hat{P}$ whose distribution is unknown. In order to have an approximation to the probability that the PMP estimator $\hat{P}$ may be smaller or greater than the quantile $\hat{P}_{d}$, Salas et al. (2014) suggested applying Chebyshev's inequality, which can be expressed as

$$
P[E(\hat{P})-c \sigma(\hat{P})<\hat{P}<E(\hat{P})+c \sigma(\hat{P})] \geq 1-\frac{1}{c^{2}}
$$

This inequality gives a bound of the probability which does not depend on the distribution of $\hat{P}$. As expected, the probability bound is conservative since one only knows the mean and the standard 
deviation of $\hat{P}$ but not its distribution. Applications of this technique can be found in Salas et al. (2014) and Singh et al. (2018a).

\section{Statistical Alternatives for Estimating PMP: Probabilistic and Stochastic Methods}

Apart from the "standard" statistical method to estimate the PMP, which is based on the seminal work of Hershfield $(1961,1965,1977)$, many methods were devised that introduce a probabilistic component. These efforts do not only aim to assess the PMP value but also to tackle the major point of criticism of the PMP concept. Recall that, PMP entails an estimated precipitation depth (over a given area, duration, and season) that cannot be exceeded. Yet this assumption has been shown to be unrealistic due to practical and conceptual arguments (e.g., Benson 1973; Dawdy and Lettenmaier 1987; Koutsoyiannis 1999; Salas et al. 2014).

In this direction, Fontaine and Potter (1989) explored the "Stochastic storm transposition" method, first introduced by Alexander (1963), further developed by Gupta (1972), and generalized by the Committee on Techniques for Estimating Probabilities of Extreme Floods (1988) The storm transposition method, a key concept in estimating the PMP, essentially allows integrating the probability of occurrence of the storm. Namely, an extreme storm occurring anywhere in a large meteorological homogeneous region is assumed to have the same probability of occurrence anywhere else in the region. This allows to extend the number of observed extreme storms and calculate more reliably the exceedance probabilities of storms at the catchment of interest. However, Foufoula-Georgiou (1989) highlighted the methodological and conceptual difficulties of this approach and provided a more rigorous probabilistic storm transposition method and stressed the importance of storm/catchment interaction.

Hubert et al. (1993) used multifractal theory to provide a formula for the possible maximum precipitation depth for a given duration and sample size. They argued that the multifractal approach 
reconciles statistics with physics as multiplicative cascades have their basis in the underlined turbulent process which leads to consistent rainfall representation. Likewise, Douglas and Barros (2003) also investigated the magnitude of extreme storms for design purposes based on multifractal methods. They suggested estimates of maximum precipitation that do not violate physical laws. The key concept was to identify the scaling laws of the observed maximum precipitation, derive an estimate based on the observations, and use multifractal scaling laws to evaluate extreme precipitation corresponding to large return periods such as $10^{6}$ years; values that may be considered in engineering practice. Also, Langousis et al. (2009) used multifractal scale invariance arguments to develop analytical expressions for intensity-duration-frequency estimation for practical applications. Casas-Castillo et al. (2018) investigated the fractal property of the rainfall intensities in Madrid, Spain and confirmed the scaling behavior of the PMP for several durations between 5 min and 24 hr. And García-Marín et al. (2019) used multifractal methods to study hourly rainfall and the annual maxima in the Umbria Region of Italy. Interestingly, Veneziano et al. (2009) argued that under stationarity and multifractality, extreme value theory cannot be applied to annual maxima; therefore, they proposed on the basis of large deviation theory and multifractal betalognormal multiplicative random cascades asymptotic results different from the classical extreme value theory. On the other hand, Veneziano and Yoon (2013) developed a unified framework of extreme precipitation analysis based on stationary multifractal models.

Papalexiou and Koutsoyiannis (2006) modified the moisture maximization method and compared the PMP estimates with those obtained by probabilistic methods concluding that the latter is more consistent with the natural behavior of extremes. Other studies focused on defining a statistical upper bound for precipitation (or floods) in the context of envelope curves. For example, Vogel et al. (2007) presented a probabilistic interpretation to regional envelope curves for floods, and Castellarin et al. (2009) extended the concept of regional envelope curves for 
rainfall, with the depth-duration envelope curves, defined as regional upper bounds on observed rainfall maxima for several rainfall durations. In addition, Viglione et al. (2012) further analyzed and tested the framework of Castellarin et al. (2009), while addressing some of its limitation and focusing on a different geographical and climatic context. Furthermore, Ben Alaya and Zwiers (2018) introduced a probabilistic method based on a bivariate extreme value distribution which accommodates the uncertainties associated to the PMP estimation. The method is based on the generalized extreme value (GEV) distribution to approximate the joint distribution of the annual extremes of two factors affecting the PMP, namely precipitable water (PW) and precipitation efficiency (PE). To account for the dependence structure between PW and PE extremes, they employed a copula function.

From a probabilistic viewpoint, the estimated PMP values correspond to specific return periods. Thus, the core idea behind PMP alternatives is using frequency analysis to estimate precipitations depths for given return periods (or exceedance probabilities), which in turn correspond to a level of risk (and reliability) that are useful for project assessment in engineering practice. There is a vast literature on frequency analysis and reviewing it is beyond the scope of this study. Yet, for completeness we summarize here the three main approaches.

The first, focuses on the analysis of block annual maxima (BAM) and dates back to the 1920's in the pioneering works of Fréchet (1927), and Fisher and Tippett (1928), who showed that there are only three limiting distributions to describe extremes, that is, the type I (Gumbel), type II (Fréchet), and type III (reversed Weibull). The formal mathematical theory was extensively applied and popularized in engineering practice by Gumbel (1958). Thus annual maxima data are conveniently analyzed using a single expression called Generalized Extreme Value (GEV) distribution as shown in Eq.(7), which unifies the three limiting laws (von Mises 1936). 


$$
F(x)=\exp \left[-\left(1+\gamma \frac{x-\alpha}{\beta}\right)^{-1 / \gamma}\right]
$$

in which $\alpha, \beta$, and $\gamma$ are the location, scale, and shape parameters, respectively and $1+$ $\gamma(x-\alpha) / \beta>0$.

For example, if the GEV distribution is fitted to annual maxima precipitation data, then the precipitation depth corresponding to any return period $T$ (in years) can be directly estimated using the GEV quantile function, $x(T)=F^{-1}(1-1 / T)$. Literature reveals an extensive discussion on the methods used to estimate the parameters with popular methods being maximum likelihood, Lmoments and more (e.g. Hosking et al. 1985; Martins and Stedinger 2000; El Adlouni et al. 2007). Naturally, different fitting methods may result in different estimates. In this direction, a point of importance is the estimation accuracy of the shape parameter $\gamma$. This parameter dictates the type of limiting law and the heaviness of the tail, which in turn controls the frequency and the magnitude of extremes. Papalexiou and Koutsoyiannis (2013) in a global analysis of more than 15,000 daily records showed that the Fréchet distribution (i.e. the GEV with $\gamma>0$ ) is the appropriate choice for daily rainfall annual maxima. They suggested that the cases where $\gamma<0$ (which leads to upper bounded distributions) are an artifact of sample variations and parameter estimator bias. In this respect an unbiased estimator was proposed.

The second approach is based on peaks over threshold (POT) analysis, i.e. instead of using annual maxima, values above a certain threshold are utilized. The theoretical basis is the PickandsBalkema-de Haan theorem (Balkema and de Haan 1974; Pickands III 1975) which indicates asymptotic convergence as the threshold increases to specific type of tails. It follows the so-called generalized Pareto (GP) distribution given by 


$$
F(x)=1-\left(1+\gamma \frac{x-\alpha}{\beta}\right)^{-1 / \gamma}
$$

where $\alpha, \beta$, and $\gamma$ are the location, scale, and shape parameters, respectively. Like the GEV distribution, the GP shape parameter $\gamma$ indicates the type of tail, that is, power-type for $\gamma>0$, exponential for $\gamma \rightarrow 0$, and with an upper bound for $\gamma<0$. Once the parameters of the GP are estimated, the corresponding depth for any return period $T$ can be determined by inverting Eq. (8). Serinaldi and Kilsby (2014) in a global analysis of POT data of daily rainfall showed that the GP shape parameter is always positive, leading to distributions without an upper bound.

Although using the GEV and GP has been the standard approach in analyzing extremes, it should be stressed that both distributions emerge as limiting laws. Convergence to the GEV distribution is achieved assuming that the maximum value is extracted from a sample of size tending to infinity; clearly, this is not the case in real world, e.g., for daily precipitation values (assuming a typical probability dry of $80 \%$ ) the annual maximum is extracted from $20 \% \times 365=$ 73 daily values (varying also from year to year). Similarly, POT values converge to the GP distribution given that the threshold tends to infinity, and yet in practice a finite threshold is always selected. This implies that for all finite samples, convergence is not guaranteed. The interpretation of the infinity assumption in practice is that a large sample size and a large threshold are necessary to assure convergence. In some cases, converge is rapidly achieved; if the maximum value is extracted from samples generated by a power-type distribution or the exponential (i.e. the parent distributions) then the convergence to the Fréchet and Gumbel distributions, respectively, is fast. This is because the Fréchet and Gumbel distributions have power-type and exponential tails, respectively, and match the tails of the parent distributions. However, if the parent distribution has a stretched exponential tail (heavier than the exponential but thinner than a power-type) then 
convergence is practically never achieved. However, based on extreme value theory the BAM and POT values should converge to the Gumbel and the exponential distributions, respectively. An alternative general method to the classical POT analysis, that tackles the convergence issue, was proposed by Papalexiou et al. (2013) where instead of using the GP distribution to describe POT data different type of tails are fitted to these values. This allows fitting and using tails of any distribution, such as, the Weibull, Lognormal, and Gamma, and then, select the best performing, rather than assuming convergence to the GP distribution which might not hold.

In the third approach, one can assume a probability distribution that is consistent with all nonzero values and describes also adequately the extremes. For example, Papalexiou et al. (2018a) estimated hourly precipitation depths at any return period by fitting distributions to the whole sample of nonzero hourly values focusing on robust tail representation based on regional tail estimates. In general, the depth $x(T)=F_{X}^{-1}\left\{1-\left[\left(1-p_{0}\right) k T\right]^{-1}\right\}$, where $T$ is the return period in years, $p_{0}$ is the probability dry years (number of zeros over total number of values), and $k$ is a constant to express $T$ in years (for example, if we deal with daily values then $k=365$ days/year). For daily precipitation, global analyses of more than 15,000 daily precipitation records (Papalexiou and Koutsoyiannis 2012, 2016) showed that two-parameter distributions are in general inadequate to describe all nonzero rainfall. Instead, flexible distributions such as the Generalized Gamma (GG), the Burr XII (BrXII), or, the Burr III (BrIII) (e.g. Papalexiou 2018) were suggested as more appropriate models for nonzero rainfall. The cumulative distribution and probability density functions for the BrXII and GG distributions are given respectively by

$$
F_{\mathcal{B} r \mathrm{XII}}\left(x ; \beta, \gamma_{1}, \gamma_{2}\right)=1-\left[1+\gamma_{2}\left(\frac{x}{\beta}\right)^{\gamma_{1}}\right]^{-\frac{1}{\gamma_{1} \gamma_{2}}}
$$




$$
f_{\mathcal{G}}\left(x ; \beta, \gamma_{1}, \gamma_{2}\right)=\frac{\gamma_{2}}{\beta \Gamma\left(\gamma_{1} / \gamma_{2}\right)}\left(\frac{x}{\beta}\right)^{\gamma_{1}-1} \exp \left[-\left(\frac{x}{\beta}\right)^{\gamma_{2}}\right]
$$

These models are illustrated using a synthetic 100-year sample (Papalexiou 2018) representing daily rainfall (Fig. a). The annual maxima are extracted and the GEV distribution is fitted and compared with the empirical values (Fig. b). Next, the 100 larger daily values are identified and used for fitting the GP distribution (Fig. c). And, the whole sample of nonzero values is used to fit the BrXII and GG distributions (Fig. d).
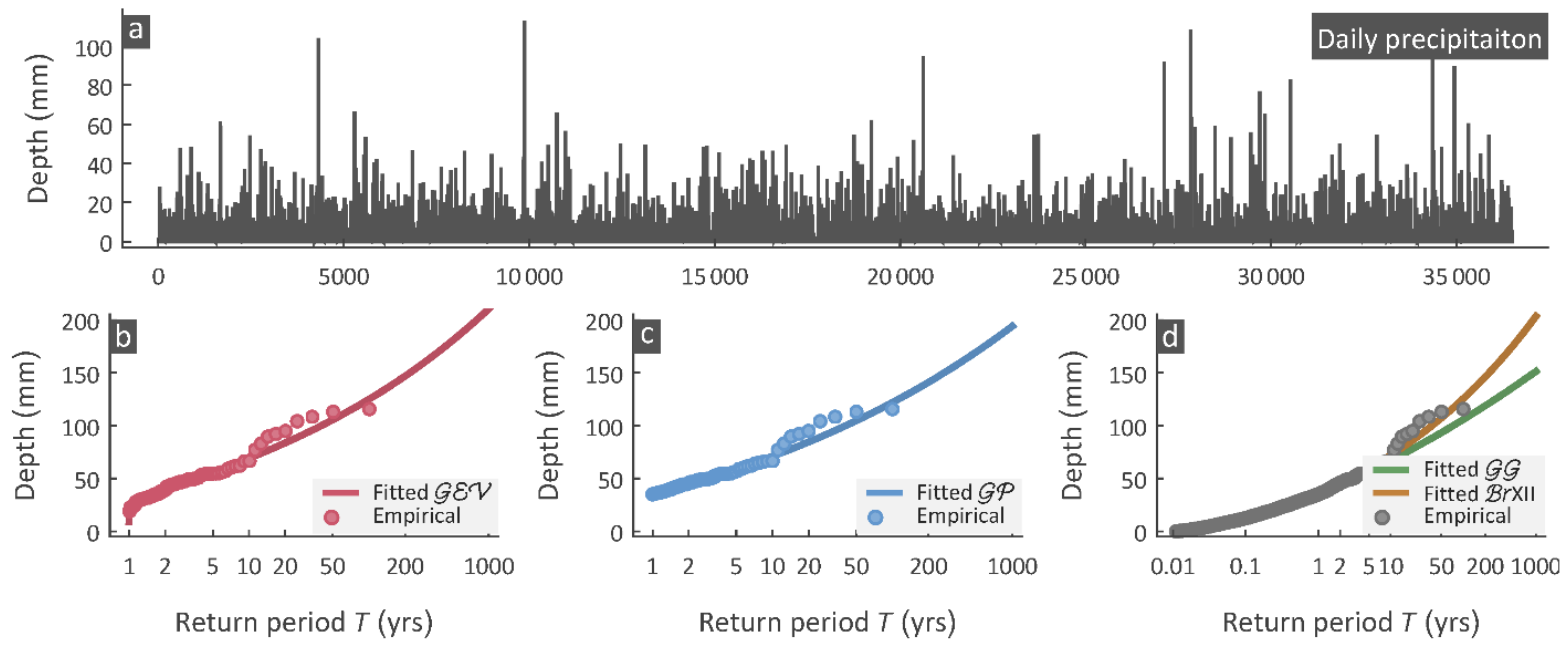

Fig. 2. Example of using different approaches to estimate rainfall depths for large return periods that could be considered as estimates of the PMP. (a) Daily precipitation time series, (b) fitted GEV distribution to annual maxima, (c) fitted GP distribution to POT data, and (d) fitted BrXII and GG distributions to the whole sample of nonzero values.

The suggested analysis could be applied to obtain an estimate of the PMP. For this purpose, the precipitation depth corresponding to a large return period can be determined consistent with a desired acceptable risk. For example, for $T=1,000$ years the GEV, GP, BrXII, and GG, distributions give rainfall depths of $210.5 \mathrm{~mm}, 194.1 \mathrm{~mm}, 203.5 \mathrm{~mm}$, and $151.3 \mathrm{~mm}$, respectively. For comparison, the PMP value obtained using Hershfield's method with $k_{m}=15$ (the maximum frequency factor given by Hershfield) is $351.2 \mathrm{~mm}$ which corresponds to a return period $T \cong$ 
11,000 years based on the fitted GEV. However, note that the value of $k_{m}$ taken in the example is the maximum value and smaller values of $T$ would result for smaller values of $k_{m}$. In addition, note that the GEV, GP, and BrXII models are expected to give close estimates since they have equivalent tails, i.e., power-law tails, while the GG model, which is of exponential form with thinner tail, gives lower depths. Therefore, the effect of the tails of the underlying distribution is crucial, since one may either overestimate or underestimate the precipitation depth depending on the type of tails of the distribution. For example, global analysis on daily rainfall conducted by Papalexiou \& Koutsoyiannis (2016) showed that the GG distribution performed better than the power-type BrXII, while in another global analysis the Weibull (with stretched-exponential tail) was proposed for daily rainfall (Wilson and Toumi 2005). Furthermore, the analysis of more than 4,000 hourly precipitation records all over the U.S. showed that stretched exponential tails performed better than power-type (Pareto) tails (Papalexiou et al., 2018). This study also revealed converge issues for the Pareto tail as the threshold selection of the POT values affected the estimation of the parameter that quantifies its heaviness. In contract, the stretched-exponential tail was robust and had the same heaviness for all thresholds tested. This is exactly the case when the parent distribution (describing all values at a specific scale) is not power-type (or exponential) and we are using a limiting distribution such as the GP to describe the POT values. Again, the foregoing discussion highlights the vast importance of assessing correctly the tails, i.e, the type of distribution. It is stressed again that the liming laws expressed by the GEV and GP distributions do not guarantee the accurate representation of the tails, a fact that can be demonstrated by assuming a parent distribution with a stretched exponential tail.

Finally, although probable maximum flood (PMF) is not the topic of this review, as expected it is strongly related to the PMP since as has been indicated above, the PMF is typically estimated 
by using PMP values. Whether applying probabilistic methods or not, the estimated PMP is a single value that corresponds to a given value of $T$ and does not account for clustering of high precipitation values in time (or space). This may affect severely the values of extreme flooding. Thus, as an alternative one may use consistent stochastic univariate (or multivariate) models that preserve the marginal distributions (and thus the behavior of extremes) and the correlation structure of precipitation (Papalexiou, 2018). Such models can be used to generate long time series to estimate areal PMP, and, feed hydrologic models to estimate PMF values. Finally, if low frequency components of precipitation are of relevance (e.g., caused by ENSO, PDO, AMO, etc.) they could affect estimates of the PMP and PMF. In this case, consistent time series can be generated based on recently developed disaggregation methods (Papalexiou et al., 2018) that preserve marginals and correlation structures but also are conditioned on time series at coarser time scales that can describe the low-frequency components.

There is agreement in the literature that the regime of extreme precipitation is changing due to global warming. Jakob et al. (2008) showed that extreme values of the precipitable water have an increasing trend in most of Australia; Groisman et al. (2013) reported that annual extreme daily precipitation increased in the USA during the 1958-2011 period; Papalexiou and Montanari (2019) showed an increase in the frequency of daily precipitation extremes in the period 1964-2013; and Markonis et al. (2019) showed increase in total precipitation, number of wet days and heavy rainfall events over land, to mention just a few. However, the PMP values are typically estimated based on the stationarity assumption. If stationarity is not valid anymore then the question that naturally arises is to what extent nonstationarity can affect PMP estimations.

Clark (1987) investigated the impact of changing climate on maximum moisture, maximum inflow winds, and precipitation efficiency, all of which are key factors for PMP estimation. In fact, 
Clark related the increase of atmospheric temperature to the increase of maximum moisture, resulting in increased values of PMP. More recently, Kunkel et al. (2013) studied how climate change influences the PMP on a global scale. Their results show that increasing trends in the mean and maximum water vapor concentrations cause increasing trends in the estimates of PMPs in the future climate. Thus, increasing attention to the effect of non-stationarity has been shown in literature for developing methods for estimating extreme precipitation including values of PMP. For example, Rousseau et al. (2014a) used the GEV distribution to estimate the 100-year precipitable water in the southern Province of Quebec, Canada, assuming a time-dependent location parameter. And Stratz and Hossain (2014) investigated the conditions under which the stationarity assumption can be relaxed. They considered non-stationarity in maximum precipitable water by extrapolating observed dew point trends to the future. Based on a case study in the Eastern USA, they concluded that nonstationary forcing will affect PMPs such that a $2^{\circ} \mathrm{F}$ increase in the average dew point can cause a10\% increase in the future PMP.

Likewise, probabilistic estimates of PMP based on nonstationarity distribution functions may be developed for evaluating and assessing future projects to include the effect of climate variability and change. In fact, some developments in this direction have already been made based on flood data in river systems that have been affected by human intervention such as urbanization (e.g. Villarini et al. 2009; Vogel et al. 2011) and river floods and sea levels affected by climate variability and change (e.g. Salas and Obeysekera 2014). Non-stationarity has been incorporated into the GEV distribution by introducing time dependence in the location and/or scale parameters (e.g. Coles, et al. 2001; Cooley 2009); however, time-dependent shape parameter has not been suggested in general because even for stationary GEV it is quite unreliable (e.g. Coles et al. 2001). For example, Leclerc and Ouarda (2007) used a GEV distribution with linear and quadratic functions for the location parameter; Gilroy and McCuen (2012) suggested a GEV with 
exponential location and scale parameters. In general many other functional forms, such as, linear, quadratic, and exponential, can be found in the literature (e.g. Coles et al. 2001; Katz et al. 2002; Hundecha et al. 2008; Hanel et al. 2009; Villarini et al. 2010; Katz 2013). In addition, trends also can be added into the parameters of the GEV through a set of predictors or covariates (e.g. Coles et al. 2001; Towler et al. 2010; Yilmaz et al. 2017). For example, Mínguez et al. (2010) studied the influence of different covariates, with a focus on the parameter selection of the model. Several authors have used with succeed large-scale climatic indices as covariates for extreme precipitation (e.g. Katz et al., 2002; El Adlouni et al. 2007; Gao et al. 2016; Su and Chen 2019) and extreme floods (e.g. Lopez and Frances 2013; Machado et al. 2015).

A different approach is to assume the parent distribution of the rainfall population is upper bounded. As shown in the sketch of Fig. 3 the behaviour of upper-bounded and unbounded distribution functions is different particularly for medium to large values of the underlying variable. If the actual distribution has an upper bound and one fits an unbounded distribution, then there will be a significant overestimation for medium values of return periods, while large underestimation for large values of return period. Classical distributions commonly used in Hydrology such as Generalized Pareto, GEV, and Log-Pearson type III can have an upper bound, but for skewness coefficients smaller than 2, 1.14, and 0, respectively, which are unrealistic for extreme precipitation. Only highly flexible distributions as the five-parameter Wakeby distribution (Houghton 1978) or the four-parameter Kappa (Hosking and Wallis 1997) can have an upper limit with appropriate values of their shape parameters. However, the review of literature does not reveal applications of the referred distributions for PMP or PMF estimation. 


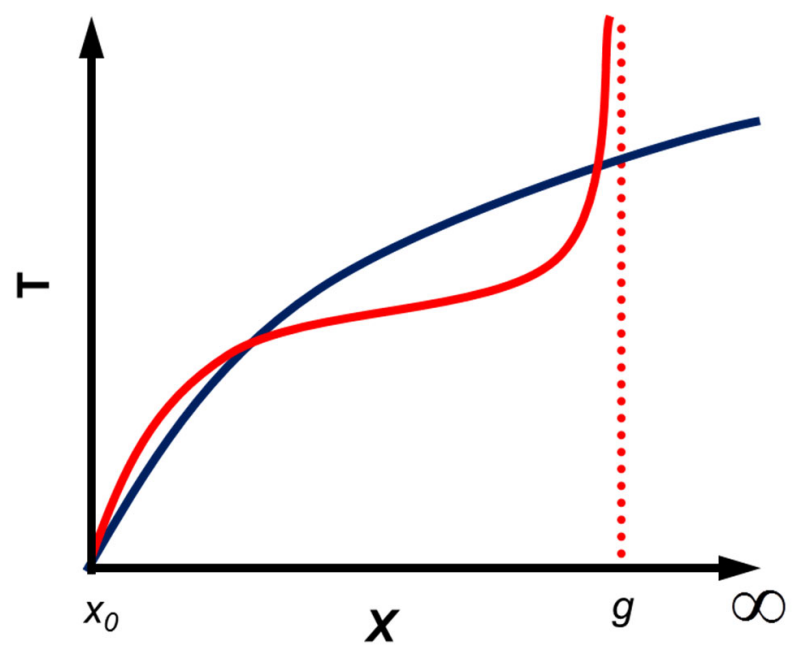

Fig. 3. Schematic comparison of upper-bounded and unbounded distributions. The horizontal scale denotes the values of the random variable $X$ (defined in the interval $x_{0}, g$ ) and the vertical scale denotes the return period $T$.

Nevertheless, there are some upper-bounded distribution functions that have been developed specifically for extreme hydrological events. The EV4 (four-parameter Extreme Value distribution function) was proposed by Kanda (1981), is an extension of the EV family. The EV4 has been used by Takara and Tosa (1999) and Botero and Francés (2010) for estimation of PMP and PMF. The LN4 (Slade-type four-parameter Log-Normal distribution function), proposed by Slade (1936) can be obtained by applying the Slade-type transformation to a Log-Normal distributed random variable. Takara and Loebis (1996), Botero and Francés (2010) and Fernandes et al. (2010) used this distribution for estimation of probable maximum hydrological events. In addition, Elíasson (1994 and 1997) defined a transformation of the Gumbel distributed variable to include an upper bound. This distribution has been used by Elíasson (1994 and 1997) and Botero and Francés (2010) for estimation of extreme precipitation and extreme floods.

In estimating the parameters of an upper-bounded distribution function, the upper bound can be estimated a priori (for example, based on meteorological methods) and then fixed (if it is an 
explicit parameter) or forced (if it is a function of other parameters). However, in some combinations of type of information, estimation method and distribution function, the estimated upper bound can be just the maximum observed value (Botero and Francés 2010), which is a useless sample estimate of the upper bound of the population. A better alternative is to estimate all parameters of the distribution function, including the upper bound, in the same estimation process. For example, one may use the upper bound estimator proposed by Cooke (1979), which is based on order statistics theory. Cooke (1979) demonstrated that it is asymptotically more efficient than the maximum observed value. Assuming the distribution function is known, the estimator of the upper bound is given by:

$$
\hat{g}=x_{\max }+\int_{-\infty}^{g}\left[F_{X}(x ; \underline{\Theta})\right]^{n} d x
$$

where $x_{\max }$ is the maximum observed value, $n$ is the observed sample size, $g$ is the upper bound, and $\underline{\Theta}$ represents the parameter set of the distribution function $F_{X}$. This approach has been used by Kijko (2004) for earthquakes and Botero and Francés (2010) for extreme floods. In addition, Cooke (1979) also suggested a non-parametric estimator of the upper bound.

Furthermore, a Bayesian approach can be used for estimating the parameters of the assumed distribution function, incorporating a previous deterministic estimation of the upper bound and, at the same time, its uncertainty through the prior distribution of the upper bound. For example, Fernandes et al. (2010) used the Bayesian framework with an EV4 distribution function, determining the prior distribution of the upper bound (the PMF in this case) from a pool of estimated values in the USA. The problem of dealing with low frequency events (where PMP and PMF are special cases) is the large uncertainty in the estimators of parameters and quantiles due to the lack of information of these very large events (Merz and Blöschl 2008). The best way of 
reducing this uncertainty is increasing the amount of information used in the estimation process. In the case of precipitation, regional analysis is a common procedure, while for floods it may be possible using additional historical and/or palaeoflood data in order to improve the estimator of the upper bound. This technique has been useful in the case of PMF estimation as shown by Botero and Francés (2010) where it was possible to estimate the upper bound with reasonable reliability.

\section{Guidelines for Estimating PMP}

Work on extreme precipitation and PMP estimates extends to many countries and locations worldwide using several procedures and comparing and evaluating them. The interest is not only for advancing knowledge but for updating existing guidelines and standards that are applicable for regions and countries. For example, Thuy et al. (2019) use historical data and future climate scenarios to evaluate PMP for three provinces in Vietnam. Kim et al. (2019) evaluate seven datasets for precipitation extremes in Southeast Asia. Rezacova et al. (2005) discuss the development of PMPs for the Czech Republic while Casas et al. (2011) provided PMP estimates for the Barcelona region in Spain and Casas-Castillo et al. (2016) assessed the PMP estimates for the region of Madrid and the Iberian Peninsula based on the statistical method and scaling procedures. Guidelines in India (Bureau of Indian Standards 1985) recommend for large reservoirs (capacity larger than $60 \mathrm{Mm} 3$ or dam higher than $50 \mathrm{~m}$ ) the use of PMF for the design flood. In some countries not using the PMP, the guidelines for evaluating and designing flood related structures are based on extreme floods with very high return periods, ranging from 500 to 10,000 years, depending on the type of structure and the risk of losses downstream. The section on "PMP Based on Hydrometeorological Methods" summarizes the various methods and standards used in the United States (US). Further description for some other countries is provided below.

\section{Guidelines in Canada}


More than 15,000 dams have been built in Canada with safety standards that are based on the concept of Probable Maximum Flood (PMF) (Canadian Dam Association, 2013). The estimated PMF's are typically derived based on PMP estimates. Yet specifically for Canada and cold regions it is highlighted that factors such as snowpack, upstream regulations and reservoir capacity, can affect the run off and thus PMF estimates (Clavet-Gaumont et al. 2017). The Canadian Dam Association uses the same PMP definition and methods suggested by WMO (refer to the Introduction section above.) In an older study the Hershfield method was used and a high frequency factor $\left(k_{m}=30\right)$ was suggested for the daily scale (McKay, 1965). Mathier et al. (1994) report that "most PMP studies in Northern Canada are based on the transposition and maximization of storms that occurred in the southern part of the country". Water Resource Consultants Ltd. (2009) mention that current practice uses sophisticated and physically based methods to derive the PMP for a specific basin.

The need to understand the risks that climate change poses to Canadian dams led to a largescale partnership of the Ouranos Consortium (2015) with dam owners, regulators, and academics, in order to review existing estimating methods of PMP/PMF and propose credible solutions to quantify climate change impacts on PMP/PMF estimates. Some studies also explored the use of Regional Climate Models (RCM's) to estimate PMP values. For example, Beauchamp et al. (2010) based on RCM's suggested summer and fall PMP increases of $0.5-6 \%$ for the $2071-2100$ period; Rousseau et al. (2014b) and Rouhani and Leconte (2016) also used RCM's and showed similar increases for several Canadian basins; and, Clavet-Gaumont et al. (2017) provided an overview and reported future increases in spring PMP for five Canadian watersheds.

\section{Guidelines in European Countries}


Estimation of extreme precipitation in the United Kingdom (UK) has been generally based on the procedures established in the Flood Studies Report (FSR) developed by the Natural Environment Research Council (NERC 1975) and updated by the Center for Ecology and Hydrology (CEH 1999). They are used for estimating extreme precipitation for return periods of 100 - 10,000 years. It is essentially based on fitting the GEV and Logistic distributions. The UK guidelines for PMP estimation are described in volume 4 of the Flood Estimation Handbook (FEH) developed by CEH (1999). The PMP over a point is based on the Estimated Maximum Precipitation (EMP) for different durations in UK considering two different seasons: May to October and November to April. These EMPs are obtained by the combination of maximum observations and the theoretical maximum precipitable water in a vertical column of the atmosphere. The PMP hyetograph takes the EMP for every duration, with no compensating reduction of maximum intensities, and nests them centrally. Concerning the spatial distribution of the PMP, CEH (1999) recommends using the areal mean of the EMPs over the catchment. Since 1999, both the FSR and FEH have been the design standards for UK where the FSR method is applied for the 10,000-year return period estimates.

A review of rainfall-frequency estimation methods has been made by Svensson and Jones (2010). They include a table summarizing the rainfall-frequency estimation methods including the PMP applied in various countries. The authors conclude that "there is a considerable difficulty in estimating long return periods rainfall from short data records and there is no obviously "best" way of doing it. Each country's method is different, but most use some form of regionalization to transfer information from the surrounding sites to the target point .... Different statistical distributions and fitting methods are used in different countries, with the GEV distribution being the most common." A recent review paper emphasizes the PMP estimation in various countries (Johnson and Smithers 2019) including UK, US, Australia, and South Africa. The paper reviews 
in some detail the PMP estimation methods by WMO, the underlying uncertainties including climate variability and change, and suggest as a good practice to compare the PMP estimation based on alternative methods as well as the importance of updating periodically the design standards to include new data and knowledge because generally the estimated PMPs do not take into account recent extreme events.

Dyrrdal (2012) provided a revision of extreme precipitation in Norway. The report indicates that the 1000-year return period precipitation and the PMP are based on WMO methods. They are applied for flood estimation in Norway depending on the type of structures. The author also indicates that extrapolation of extremes events is commonly used based on the GEV distribution. The PMP is estimated following the methods used by NERC in UK. Since Norway has a complex topography the extreme precipitation method developed by NERC for Scotland/North Ireland is most suitable for Norwegian conditions. A table is included summarizing the various methods for estimating extreme precipitation and the PMP for some countries such as US, Canada, Australia, Iceland, and various European countries.

An important document for European countries on extreme events is the European Flood Risk Directive (European Commission 2007) that requires member states to consider the impact of climate change in the flood frequencies for the flood risk assessment and management.

\section{Guidelines in Australia}

Estimates of PMP in Australia are used for dam design. And rainfall frequency estimation in the range 50-2000 years return periods is based on FORGE method developed at the Institute of Hydrology of UK (Reed and Stewart 1989). For return periods bigger than 2000 years up to the PMP for various durations a generalized procedure is followed (Siriwardena and Weinmann 1998). Estimates of PMP are available from the Bureau of Meteorology of Australia. The estimation of 
rainfall design depths considers frequency analysis, regional analysis, and "pragmatic" extrapolation. The design characteristics include design event classes in the range 50-100, 1002000, and 2000-10 $0^{7}$ years return periods for large, rare, and extreme events, respectively (Nathan and Merz 2001). A credible limit of extrapolation is the point corresponding to 2000-year return period, i.e. the point corresponding to the annual exceedance probability (AEP) of $1 / 2000$. The authors point out that the design guidelines in Australia have moved towards a risk-based approach and for this purpose it is necessary to have estimation procedures of extreme precipitation (and corresponding extreme floods) all the way to the PMP/PMF values. The referred paper includes figures and tables that clearly show the concepts. They also illustrate the considerable uncertainty involved in the extrapolated estimates and indicate that "although the probabilities are subjective, they do reflect the considerable uncertainty in the AEP estimates" (Nathan and Merz 2001.) Recent research for estimating the AEP for extreme precipitation up to the PMP with applications in some Australian catchments shows promising results (Natham et al. 2016).

In 2009 a study was undertaken to assess how the various factors used for estimating the PMP in Australia may change over time. The factors included local moisture availability, storm types, depth-duration-area curves, and relative storm efficiency. In addition, the study used GCMs projections for assessing changes in observed rainfall. The $90 \%$ of moisture availability was compared for periods 1960-1980 and 1981-2003. The results showed significant increases along parts of the east coast but also a region of decrease in south-eastern Australia for the Summer. For assessing the projected changes in moisture availability, the CSIRO MK3.0 model was used considering three greenhouse gas emissions scenarios: A2, A1 B, and B1. The 90 percentile of the moisture availability tends to increase for future decades and as expected the increase is more pronounced for the A2 scenario. The authors caution though that the results are based on only one model and higher degree of reliability would be obtained using a range of GCMs. After considering 
and analyzing various results the report states that based on likely changes to maximum moisture and maximum storm efficiency, the investigations did not lead to conclude that PMP estimates would definitely increase under a warming climate. The authors acknowledge some limitations involving the resolution of the GCMs outputs, the assumption that PMP does indeed occurs under maximum moisture availability, and the use of alternative measures of storm efficiency. And they suggest that future investigations should also consider assessing separately the effects of thermodynamics and dynamical components. The report also indicates that global climate models do not accurately make the trends of late $20^{\text {th }}$ Century Australian rainfall but due to the overall increase in moisture availability in a warming climate, extreme rainfall is likely to increase in the $21^{\text {st }}$ Century.

\section{Final Comments and Remarks}

- Determine potential changes in the spatial and temporal scale of conditions that lead to the PMP. This includes assessing the critical duration of the extreme precipitation as well as the influence of antecedent conditions

- Develop more process driven studies that simulate how the land surface and atmosphere interact during precipitation extremes. This would include land cover influences on the surface boundary layer and the influence of moist air transport over snow-covered watersheds.

- Determine temporal frames where different influences of change are likely to dominate the PMP process. The next few decades may be driven by one process that gives way to others as more extreme warming takes place.

- Statistical methods on estimating the PMP have been widely used in engineering practice. They are appealing as they are easy to apply and as any PMP method the estimated depth is assumed that cannot be exceeded, offering thus, risk free design depts. Yet this assumption is the 
Achilles' heel of PMP methods as reality has shown many cases where PMP estimates have been exceeded.

- The main alternative is using probabilistic methods that estimate rainfall depths corresponding to very large return periods which offer an acceptable risk in engineering practice. Several different approaches have been used that focus on the analysis of annual maxima, peak over threshold values, multifractal techniques, or using distributions to describe the whole sample of precipitation values. Recent global analyses offer a clearer picture on the probabilistic behavior of precipitation and an opportunity of robust estimates of large return levels.

- The increased water vapor content in the atmosphere due to global warming is expected to alter the precipitation properties and the behavior of extremes. This led into considering nonstationary methods for estimating the PMP that either are based on adopting a nonstationary distribution to estimate large return levels, or, using climate model projections.

- Whether or not decision makes and stakeholders agree on the effects of climate variability and change on PMP estimates, the review of literature suggest that given the complexity of the underlying thermodynamics and the dynamics of the processes involved, the estimation of PMP must include the effects of uncertainties and rather that estimating a single PMP value, provide a range of possible values and preferably the probability distribution of PMP.

- Further extend the method for determining the uncertainty of the PMP estimator based on the traditional statistical method considering the effect of the factor $K_{m}$ in addition to the sample mean and the standard deviation. This may be possible since $K_{m}$ is a function of the sample mean and the storm duration. Likewise, consider the effect of climate change scenarios on the factors determining the PMP estimator.

\section{Acknowledgments}


We would like to acknowledge the support of the Global Water Futures Program and the Natural Sciences and Engineering Research Council of Canada (NSERC Discovery Grant: RGPIN-201906894). The 4rd author acknowledges the support of the Spanish Ministry of Science and Innovation, Project TETISCHANGE (RTI2018-093717-B-100). The $1^{\text {st }}$ author appreciates the continuous support from the Scott College of Engineering of Colorado State University.

\section{References}

Abbs, D. (1999), "A numerical modeling study to investigate the assumptions used in the calculation of probable maximum precipitation", Water Resources Research, Vol 35, Issue 3, 785-796.

Alexander, G. N. (1963). "Using the probability of storm transposition for estimating the frequency of rare floods." Journal of Hydrology, 1(1), 46-57.

Alias, N.E., Luo, P., and Takara, K. (2013). "Probable maximum precipitation using statistical method for the Yodo River basin." Jour. Japan Society of Civil Engineers, Ser. B1 (Hydraulic Engineering), 69(4), I_157 - I_162.

Balkema, A. A., and de Haan, L. (1974). "Residual Life Time at Great Age." The Annals of Probability, 2(5), 792-804.

Barker, B., Schaefer, M.G., Mumford, J., and Swain, R., 1997. "A Monte Carlo approach to determine the variability of PMF estimates", Final Report on Bumping Lake Dam for USBR Dam Safety Office.

Beauchamp, J. (2010). "Estimation d'une PMP et d'une CMP d'un bassin versant septentional, en contexte de changements climatiques." masters, École de technologie supérieure, Montréal.

Beauchamp, J., Leconte, R., Trudel, M., and Brissette, F. (2013). "Estimation of the summer-fall PMP and PMF of a northern watershed under a changed climate", Water Resour. Res., 49, 3852-3862.

Ben Alaya, M. A., Zwiers, F., and Zhang, X. (2018). "Probable Maximum Precipitation: Its Estimation and Uncertainty Quantification Using Bivariate Extreme Value Analysis." Journal of Hydrometeorology, 19(4), 679-694.

Benson, M. A. (1973). "Thoughts on the design of design floods. Floods and droughts." Proceedings of the 2nd International Symposium in Hydrology, Water Resources Publications, Fort Collins, CO, 27-33.

Botero, B.A. and Frances, F. 2010. "Estimation of high return period flood quantiles using additional non-systematic information with upper bounded statistical models." Hydrol. Earth Syst. Sci. 14, 2617-2628, EGU. 
BMA (Bureau of Meteorology of Australia), 2009. "Climate change and probable maximum precipitation." HRS Report No. 12.

Casas, C.M., Rodríguez, R., Nieto, R. and Redaño, A. 2008. "The estimation of probable maximum precipitation, the case of Catalonia." In Trends and Directions of Climate Research, Ann. N.Y. Acad. Sci. 1146, 291-302.

Casas-Castillo, M. C., Rodríguez-Solà, R., Navarro, X., Russo, B., Lastra, A., González, P., and Redaño, A. (2018). "On the consideration of scaling properties of extreme rainfall in Madrid (Spain) for developing a generalized intensity-duration-frequency equation and assessing probable maximum precipitation estimates." Theoretical and applied climatology, 131(1-2), $573-580$.

Castellarin, A., Merz, R., and Blöschl, G. (2009). "Probabilistic envelope curves for extreme rainfall events." Journal of Hydrology, 378(3), 263-271.

Chavan, S. R., and Srinivas, V. V. (2017). "Regionalization based envelope curves for PMP estimation by Hershfield method." International Journal of Climatology, 37(10), 3767-3779.

Chen, L. C. and Bradley, A. A. (2003). "The dependence of the moisture maximization in PMP procedures on spatial scale", in Proceedings of the $17^{\text {th }}$ Conf. on Hydrology, AMS, Paper P1.6.

Chen X., Hossain, F., and Leung, L. R. (2017): "Probable maximum precipitation in the US Pacific Northwest in a changing climate", Water Resour. Res., 53, 9600-9622.

Chow, V. T. (1951). "A general formula for hydrologic frequency analysis.” Trans. Am. Geophys. Union, 32, 231-237.

Chow, V. T., Maidment, D. R., and Mays, L. W. (1988). Applied hydrology, McGraw Hill Book, Co., N.Y.

Clark, R. A. (1987). "Hydrologic design criteria and climate variability." IAHS Publication, 168, 640.

Clavet-Gaumont, J., Huard, D., Frigon, A., Koenig, K, Slota, P., Rousseau, A., Klein, I., Thiemonge, N., Houndre, F., Perdikaris, J., Turcotte, R., Lafleur, J., and Larouche, B. (2017): "Probable maximum flood in a changing climate: an overview for Canadian basins", J. Hydrol: Reg. Studies, 13, 11-25.

Coles, S., Bawa, J., Trenner, L., and Dorazio, P. (2001). An introduction to statistical modeling of extreme values. Springer.

Collier, C.G. and Hardaker, P.J. (1996). "Estimating probable maximum precipitation using a storm model approach.” J. Hydrol. 183, 277-306.

Commonwealth Bureau of Meteorology (2003). "The estimation of probable maximum precipitation in Australia: generalized short duration method", Hydrometeorological Advisory Service. 
Cooke, P. (1979). "Statistical inference for bounds of random variables". Biometrika, 66, 367-374.

Cooley, D. (2009). "Extreme value analysis and the study of climate change." Climatic Change, 97(1), 77.

Corrigan, P., Fenn, D.D., kluck, D.R., and Vogel, J.L. (1999). "Probable maximum precipitation for California”, National Weather Service Hydrometeorological Report No. 59, 392 pages.

Dawdy, D.R. and Lettenmaier, D.P. (1987). "Initiative for risk-based flood design." ASCE $J$. Hydrau. Engr. 113(8), 1041-1051.

Dwyer, I. J. and Reed, D. W. (1994). "Effective fractal dimension and corrections to the mean of annual maxima." J. Hydrol., 157, 13-34.

Desa, M.N. and Rakhecha, P.R. (2007). "Probable maximum precipitation for 24-hr duration over an equatorial region: Part 2-Johor, Malaysia." Atmospheric Research, 84, 84-90.

Dettinger, M., "Climate Change, Atmospheric Rivers, and Floods in California - A Multimodel Analysis of Storm Frequency and Magnitude Changes", Journal of the American Water Resources Association, 47(3), 514-523.

Dhar, O.N., Kulkarni, A.K., and Rakhecha, P.R. (1980). "Probable maximum point rainfall estimation for the southern half of the Indian peninsula." Proc. Indian Acad. Sci. (Earth Planet. Sci.), 90(1), 39-46.

Diaz, A. J., K. Ishida, M. L. Kavvas, and M. L. Anderson, (2017). Maximum Precipitation Estimation for Five Watersheds in the Southern Sierra Nevada. Proceedings of the 2017 World Environmental and Water Resources Congress, 331-339.

Dorte, J. et al. (2009). "Climate change and probable maximum precipitation", HRS No.12, Australian Government Bureau of Meteorology, Hydrometeorological Advisory Service, Water Division, Melbourne.

Douglas, E.M. and Barros, A.P. (2003). "Probable maximum precipitation estimation using multifractals: application in the eastern United States." J. of Hydrometeorology, 4, 1012-1024.

Dyrrdal, A.V. (2012). "Estimation of extreme precipitation in Norway and a summary of the stateof-the-art." Norwegian Meteorological Institute, Report No. 08/2012, 19 pages.

El Adlouni, S., Ouarda, T. B. M. J., Zhang, X., Roy, R., and Bobée, B. (2007). "Generalized maximum likelihood estimators for the nonstationary generalized extreme value model." Water Resources Research, 43(3).

Elíasson, J. (1994). "Statistical estimates of PMP values.” Nordic Hydrology, 25, 301-312. 
Elíasson, J. (1997). "A statistical model for extreme precipitation.” Water Resour. Res., 33 (3), 449-455.

England, J. F., Jarrett, R. D., and Salas, J. D. (2004). "Data-based comparisons of moment estimators using historical and paleoflood data." J. Hydrol., 278, 172-196.

England, J.F., Jarrett, R.D., and Salas, J.D. 2003. "Comparisons of two moment-based estimators that utilize historical and paleoflood data for the log-Pearson type III distribution", Water Resour. Res. 39(9), p. 1243, doi:10.1029/2002WR001791.

England, J.F. (2011). "Flood frequency and design flood estimation procedures in the United States: Progress and challenges", Australian Journal of Water Resources, 15(1).

England, J.F., Sankovich, V.L., and Caldwell, R.J. (2011). "Review of Probable Maximum Precipitation Procedures and Databases Used to Develop Hydrometeorological Reports", U.S.B.R., Report for the Nuclear Regulatory Commission, Dec.

European Commission (2007). "Directive 2007/60 EC of the European Parliament and of the Council of 23/10/2007 on the Assessment and Management of Flood Risk".

Fernandes, W., M. Naghettini, and R. Loschi (2010). “A Bayesian approach for estimating extreme flood probabilities with upper-bounded distribution functions." SERRA, 24, 1127-1143.

Fernando W.C.D.K. and Wickramasuriya, S. (2010). "The hydrometeorological estimation of probable maximum precipitation under varying scenarios in Sri Lanka", Inter. J. of Climat. 31(5), 668-676.

Fisher, R. A., and Tippett, L. H. C. (1928). "Limiting Forms of the Frequency Distribution of the Largest or Smallest Member of a Sample." Mathematical Proceedings of the Cambridge Philosophical Society, 24(02), 180-190.

Fontaine Thomas A., and Potter Kenneth W. (1989). "Estimating Probabilities of Extreme Rainfalls.” Journal of Hydraulic Engineering, 115(11), 1562-1575.

Foufoula-Georgiou, E. (1989). "A probabilistic storm transposition approach for estimating exceedance probabilities of extreme precipitation depths." Water Resources Research, 25(5), $799-815$.

Francés, F., Salas, J. D., and Boes, D. C. (1994). "Flood frequency analysis with systematic and historical or paleoflood data based on the two-parameter general extreme value models." Water Resour. Res., 30(5), 1653-1664.

Francés, F. (1998). "Using the TCEV distribution function with systematic and non-systematic data in a regional flood frequency analysis." Stochastic Hydrology and Hydraulics, 12(4), 267283.

Fréchet, M. (1927). "Sur la loi de probabilité de l'écart maximum." Ann. soc. polon. math, 6, 93.

Gao, M., Mo, D., Wu, X. (2016). "Nonstationary modeling of extreme precipitation in China." Atmospheric Research, 182(15), 1-9. 
García-Marín, A. P., Morbidelli, R., Saltalippi, C., Cifrodelli, M., Estévez, J., and Flammini, A. (2019). "On the choice of the optimal frequency analysis of annual extreme rainfall by multifractal approach." Journal of Hydrology.

Gilroy, K. L., and McCuen, R. H. (2012). "A nonstationary flood frequency analysis method to adjust for future climate change and urbanization." Journal of Hydrology, 414, 40-48.

Graham, W.J. (2000). "Should dams be modified for the probable maximum flood?, JAWRA, 36(5), 953-963.

Groisman, P. Y., Knight, R. W., and Zolina, O. G. (2013). "Recent trends in regional and global intense precipitation patterns." Climate vulnerability, 5, 25-55.

Gumbel, E. J. (1958). Statistics of Extremes. Columbia University Press.

Gupta, V.K., (1972). "Transposition of storms for estimating flood probability distributions", Hydrology Papers 59, Colorado State University, Fort Collins, Colorado.

Hanel, M., Buishand, T. A., and Ferro, C. A. (2009). "A nonstationary index flood model for precipitation extremes in transient regional climate model simulations." Journal of Geophysical Research: Atmospheres, 114(D15).

Hansen, E.M. Schreiner, L.C., and Miller, J.F. (1982). "Application of Probable Maximum Precipitation Estimates - United States East of $105^{\text {th }}$ Meridian", Hydrometeorological Report 52, U.S. Department of Commerce, NOAA, U.S. Weather Bureau, Washington D.C.

Hansen, E.M. (1987). "Probable maximum precipitation for design floods in the United States", $J$. Hydrol. 96, 267-278.

Hansen, E.M., Fenn, D.D., Schreiner, L.C., Stodt, R.W., and Miller, J.F. (1988). "Probable maximum precipitation estimates - United States between the Continental Divide and the $103^{\text {rd }}$ Meridian", Hydrometeorological Report No. 55A, National Weather Service, NOAA, U.S. Department of Commerce, Silver Spring, MD, 168 p.

Hershfield, D. M. (1961). "Estimating the probable maximum precipitation." Proc. ASCE, J. Hydraul. Div, 106.

Hershfield, D. M. (1965). “Method for estimating probable maximum rainfall.” Journal-American Water Works Association, 57(8), 965-972.

Hershfield, D. M. (1977). "Some tools for hydrometeorologists", $2^{\text {nd }}$ Conference on Hydrometeorology, American Meteorological Society, Boston, MA.

Ho, F.P. and Riedel, J.T., (1980). "Seasonal variation of 10-square-mile probable maximum precipitation estimates, United States East of the $105^{\text {th }}$ Meridian", Hydrometeorological Report No. 53, National Weather Service, NOAA, U.S. Department of Commerce, Silver Spring, MD, $168 \mathrm{p}$.

Hosking J.R.M. and J.R. Wallis (1997). "Regional frequency analysis—an approach based on Lmoments." Cambridge University Press, Cambridge. 
Hosking, J. R. M., Wallis, J. R., and Wood, E. F. (1985). "Estimation of the Generalized ExtremeValue Distribution by the Method of Probability-Weighted Moments." Technometrics, 27(3), 251-261.

Hossain, F., Jeyachandran, I., and Pielke, R.A. Sr. (2010). "dam safety effects due to human alteration of extreme precipitation", Water Resour. Res., 46, W03301.

Houghton, J.C. (1978). "Birth of a parent: the Wakeby distribution for modeling flood flows. Water Resour. Res., 14(6), 1105-1109.

Hubert, P., Tessier, Y., Lovejoy, S., Schertzer, D., Schmitt, F., Ladoy, P., Carbonnel, J. P., Violette, S., and Desurosne, I. (1993). "Multifractals and extreme rainfall events." Geophysical Research Letters, 20(10), 931-934.

Hundecha, Y., St-Hilaire, A., Ouarda, T., El Adlouni, S., and Gachon, P. (2008). "A nonstationary extreme value analysis for the assessment of changes in extreme annual wind speed over the Gulf of St. Lawrence, Canada." Journal of Applied Meteorology and Climatology, 47(11), 2745-2759.

Jothityangkoon, C., Hirunteeyakul, C., Boonrawd, K. and Sivapalan, M., (2013). "Assessing the impact of climate and landuse changes on extreme floods in a large tropical catchment", $J$. Hydrol., 490, 88-105.

Ishida, K., Ohara, N., Kavvas, M.L., Chen, Z.Q. and Anderson, M.L., 2016. Impact of air temperature on physically-based maximum precipitation estimation through change in moisture holding capacity of air. Journal of Hydrology. 556, 1050-1063.

Ishida, K., Kavvas, M.L., Jang, S., Chen, Z.Q., Ohara, N. and Anderson, M.L., 2015. Physically based estimation of maximum precipitation over three watersheds in Northern California: Relative humidity maximization method. Journal of Hydrologic Engineering, 20(10), p.04015014.

Ishida, K., Kavvas, M. L., Jang, S., Chen, Z. Q., Ohara, N. and Anderson, M. L., 2014. Physically based estimation of maximum precipitation over three watersheds in northern California: Atmospheric boundary condition shifting. Journal of Hydrologic Engineering, 20(4), p.04014052.

Jakob, D., Smalley, R., Meighen, J., Taylor, B., Xuereb, K., and others. (2008). "Climate change and probable maximum precipitation." Proceedings of Water Down Under 2008, 109.

Johnson, K. A. and Smithers, J. C. (2019). "Methods for the estimation of extreme rainfall events." Water $S A, 45(3), 501-512$, July.

Kanda, J. (1981). "A new value distribution with lower and upper limits for earthquake motions and wind speeds". Theoretical and Applied Mechanics, 31, 351-360.

Kao, S. C. and Ganguly, A. R. (2011). "Intensity, duration, and frequency of precipitation extremes under $21^{\text {st }}$ Century warming scenarios." J. Geoph. Res. 116, D16119, 14 pages. 
Katz, R. W. (2013). "Statistical methods for nonstationary extremes." in Extremes in a changing climate, Springer, 15-37.

Katz, R. W., Parlange, M. B., and Naveau, P. (2002). "Statistics of extremes in hydrology." Advances in Water Resources, 25(8-12), 1287-1304.

Katz, R. W., G. S. Brush, and M. B. Parlange (2005). "Statistics of extremes: modeling ecological disturbances.", Ecology, 86, 1124-1134.

Kendall, M. and Stuart, A. (1963). "The advanced theory of statistics, Vol. 1 distribution theory." $2^{\text {nd }}$ Ed., Hafner Publishing Company Inc., New York.

Kharin, V.V. and Zwiers, F. (2005). "Estimating extremes in transient climate change simulations", J. Climate, 18, 1156-1173.

Kharin, V.V., Zwiers, F., Zhang, X., and Hegerl, G.C. (2007). "Changes in temperature and precipitation extremes in the IPCC ensemble of global coupled model simulations", J. Climate, 20, 1419-1444.

Kijko, A. (2004). "Estimation of the maximum earthquake magnitude-Mmax.", Pure and Applied Geophysics, 161, 1-27.

Kim, I.W., Oh, J., Woo, S., and Kripalani, R.H. (2019). "Evaluation of precipitation extremes over the Asian domain: observation and modelling studies." Climate Dynamics, 52, 1317-1342.

Kinya Toride; Kei Ishida; Levent M. Kavvas; and Michael L. Anderson., 2017. Maximum Precipitation Estimation over Shasta Dam Watershed by Means of Atmospheric Boundary Condition Shifting Method. Proceedings of the 2017 World Environmental and Water Resources Congress, 340-346.

Klemes, V., Nikleva, S., and Chin, W.Q. (1992). "Probability of a PMP - A Feasibility Study", Dam Safety 1992, 1-16.

Klemes, V. (1993). "Probability of extreme hydrometeorological events - a different approach", Proceedings of the Yokohama Symposium, July, IAHS Pub. No. 213, 167-176.

Koutsoyiannis, D. (1999). "A probabilistic view of Hershfield's method for estimating probable maximum precipitation.” Water Resources Research, 35(4), 1313-1322.

Kulkarni, B.D., Nandargi, S., and Mulye, S.S., (2010). "Zonal estimation of probable maximum precipitation rain depths over the Krishna basin in peninsular India", Hydrol. Sci. J., 55, 93103.

Kundzewicz, Z.W. and Stakhiv, E. (2010). "Are climate models "ready for prime time" in water resources management applications, or is more research needed?", Hydrol. Sc. J. 55(7), 10851089. 
Kunkel, K. E., Karl, T. R., Easterling, D. R., Redmond, K., Young, J., Yin, X., and Hennon, P. (2013). "Probable maximum precipitation and climate change." Geophysical Research Letters, 40(7), 1402-1408.

Lagos-Zuniga and Vargas (2014): "PMP and PMF estimations in sparsely-gauged Andean basins and climate change projections", Hydrol. Sci. Jour. 59(11), 2027-2042.

Lan, P., Lin, B., Zhang, Y., and Chen, H. (2017). "Probable maximum precipitation estimation using the revised $\mathrm{K}_{\mathrm{m}}$-value method in Hong Kong", Case Study paper, ASCE J. Hydrol. Engr., 22(8), 05017008-1/05017008-8.

Langousis, A., Veneziano, D., Furcolo, P., and Lepore, C. (2009). "Multifractal rainfall extremes: Theoretical analysis and practical estimation." Chaos, Solitons \& Fractals, 39(3), 1182-1194.

Laurenson, E.M. and Kuczera, G.A., (1999). "Annual exceedance probability of probable maximum precipitation”, Australian J. Water Resources, 3(2), 167-176.

Leclerc, M., and Ouarda, T. B. (2007). "Non-stationary regional flood frequency analysis at ungauged sites." Journal of hydrology, 343(3-4), 254-265.

Lee, O, Park, Y., Kim, E.S., and Kim, S. (2016). "Projections of Korean probable maximum precipitation under future climate change scenarios", Adv. Meteorol., 3818236.

Lee, J, Choi, J., Lee, O., Yoon, J., and Kim, S. (2017): "Estimation of probable maximum precipitation in Korea using a regional climate model", Water 9, 240, 12 pages.

Liu, C.C., Yang, T.C., Kuo, C.M., Chen, J.M., and Yu, P.S. (2016). "Estimating probable maximum precipitation by considering combined effect of typhoon and southwesterly air flow", Terr. Atmos. Ocean Sci., 27(6), 991-1003.

Lin, B., and Vogel, J. (1993). “A New Look at the Statistical Estimation of PMP.” ASCE, Reston, VA, Engineering Hydrology, 629-634.

López, J. and F. Francés (2013). "Non-stationary flood frequency analysis in continental Spanish rivers, using climate and reservoir indices as external covariates." Hydrol. Earth Syst. Sci., 17, 3189-3203.

Mao, G., Vogl, S., Laux, P., Wagner, S., and Kunstmann, H. (2015). "Stochastic bias correction of dynamically downscaled precipitation fields for Germany through copula-based integration of gridded observation data", Hydrol. Earth Syst. Sci. 19, 1787-1806.

Machado, M.J., B. A. Botero, J. López, F. Francés, A. Díez-Herrero, and G. Benito (2015). "Flood frequency analysis of historical flood data under stationary and non-stationary modelling." Hydrol. Earth Syst. Sci., 19, 2561-2576.

Markonis, Y., Papalexiou, S. M., Martinkova, M., and Hanel, M. (2019). "Assessment of Water Cycle Intensification Over Land using a Multisource Global Gridded Precipitation DataSet." Journal of Geophysical Research: Atmospheres, 124(21), 11175-11187. 
Martins, E. S., and Stedinger, J. R. (2000). "Generalized maximum-likelihood generalized extreme-value quantile estimators for hydrologic data." Water Resources Research, 36(3), $737-744$.

Mathier, L., Fortin, J.-P., Bobée, B., and Perreault, L. (1994). Probable maximum precipitation $(P M P)$ in Boreal regions: phase III: analysis of rainfall data from automatic stations in Canada. INRS-Eau.

Maurer, E. et al. (2007). "Uncertainty of hydrologic impacts of climate change in the Sierra Nevada, California, under two emissions scenarios", Climatic Change, 82, 309-325.

Mejia, G. and Villegas, F. (1979). "Maximum precipitation deviations in Colombia." Third Conference on Hydrometeorology, Amer. Meteorol. Soc., Boston, Mass., p. 74-76, Aug.2024, Bogota, Colombia.

Merz, B. and Thieken, A.H. (2005). "Separating natural and epistemic uncertainty in flood frequency analysis", J. Hydrol. 309, 114-132.

Merz, R. and G. Blöschl. (2008). "Flood frequency hydrology: 1. temporal, spatial, and causal expansion of information." Water Resour. Res., 44, W08432, doi:10.1029/2007WR006744.

Micovic, Z., Schaefer, M.G., Taylor, G.H. (2015). "Uncertainty analysis for probable maximum precipitation estimates." J. Hydrol. 521, 360-373.

Mínguez, R., Méndez, F., Izaguirre, C., Menéndez, M., and Losada, I. J. (2010). "Pseudo-optimal parameter selection of non-stationary generalized extreme value models for environmental variables." Environmental Modelling \& Software, 25(12), 1592-1607.

Monette, A., Sushama, L. Khaliq, M.N., Laprise, R., and Roy, R. (2012). "Projected changes to precipitation extremes for northeast Canadian watersheds using a multi-RCM ensemble", $J$. Geophys. Res. Atmos, 117, 1-15.

Mood, A., Graybill, F., and Boes, D. C. (1974). "Introduction to the theory of statistics." $3^{\text {rd }}$ Edition, McGraw Hill, N. York.

Nathan, R.J. and Weinmann, P.E. (2001). "Estimation of Large to Extreme Floods", Book VI in Australian Rainfall and Runoff: A Guide to Flood Estimation, National Committee on Water Engineering, Institution of Engineers, Australia.

Nathan, R.J. and Merz, S.K. (2001). "Estimation of Extreme Hydrologic Events in Australia: Current Practice and Research Needs", in Hydrologic Research Needs for Dam Safety, Meeting Sponsored by FEMA, paper 13, 69-77, November.

Nathan, R., Jordan, P., Scorah, M., Lang, S., Kuczera, G., Schaefer, M., and Weinmann, E. (2016). "Estimating the exceedance probability of extreme rainfalls up to the probable maximum precipitation." Jour. Hyrol. 543, 706-720. 
National Research Council. (1988). Estimating probabilities of extreme floods: methods and recommended research. National Academy Press.

National Research Council, (1994). "Estimating Bounds on Extreme Precipitation Events", National Academy Press, Washington D.C., 29 pp.

NERC (Natural Environment Research Council), (1975.) "Flood Studies Report”, Vol. II, London, UK.

Nobilis, F., Haiden, T., and Kerschbaum, M. (1991). "Statistical considerations concerning probable maximum precipitation (PMP) in the Alpine country of Austria." Theoretical and applied climatology, 44(2), 89-94.

NRC (National Research Council), (2000). "Risk Analysis and Uncertainty in Flood Damage Reduction Studies", National Academy Press, Washington D.C., 202 pages.

NWS (National Weather Service) (1980). "Probable maximum precipitation estimates, United States between the Continental Divide and the 103rd Meridian." Hydrometeorological Report 55A, Silver Spring, MD, 259 pp.

NWS (National Weather Service) (1994). "Probable Maximum Precipitation for the Pacific Northwest States - Columbia, Snake River, and Pacific Coastal Drainages", Hydrometeorological Report No. 57, Silver Spring, MD, October.

O’Connell, D.R.H., Ostenaa, D.A., Levish, D.R., and Klinger, R.E. (2002). "Bayesian flood frequency analysis with paleoflood bound data", Water Resour. Res. 38(5), DOI 10.1029/2000WR000028, $14 \mathrm{p}$.

Ohara, N., M. L., Kavvas, M. L. Anderson, Z. Q. Chen, and K. Ishida, (2017). Characterization of Extreme Storm Events Using a Numerical Model-Based Precipitation Maximization Procedure in the Feather, Yuba, and American River Watersheds in California. Journal of Hydrometeorology, 18(5), pp.1413-1423.

Ohara, N., Kavvas, M.L., Kure, S., Chen, Z.Q., Jang, S., and Tan, E. (2011). "Physically based estimation of maximum precipitation over the American River Watershed, California", ASCE J. Hydrol. Engr., 16(4), 351-361.

Papalexiou, S. M. (2018). "Unified theory for stochastic modelling of hydroclimatic processes: Preserving marginal distributions, correlation structures, and intermittency." Advances in Water Resources, 115, 234-252.

Papalexiou, S.M. and Koutsoyiannis, D. (2006). "A probabilistic approach to the concept of probable maximum precipitation." Adv. in Geosciences, 7, 51-54.

Papalexiou, S. M., and Koutsoyiannis, D. (2012). "Entropy based derivation of probability distributions: A case study to daily rainfall." Advances in Water Resources, Space-Time Precipitation from Urban Scale to Global Change, 45, 51-57. 
Papalexiou, S. M., and Koutsoyiannis, D. (2013). "Battle of extreme value distributions: A global survey on extreme daily rainfall." Water Resources Research, 49(1), 187-201.

Papalexiou, S. M., and Koutsoyiannis, D. (2016). "A global survey on the seasonal variation of the marginal distribution of daily precipitation." Advances in Water Resources, 94, 131-145.

Papalexiou, S. M., Koutsoyiannis, D., and Makropoulos, C. (2013). "How extreme is extreme? An assessment of daily rainfall distribution tails." Hydrol. Earth Syst. Sci., 17(2), 851-862.

Papalexiou, S. M., AghaKouchak, A., and Foufoula-Georgiou, E. (2018a). "A Diagnostic Framework for Understanding Climatology of Tails of Hourly Precipitation Extremes in the United States." Water Resources Research.

Papalexiou, S. M., Markonis, Y., Lombardo, F., AghaKouchak, A., and Foufoula-Georgiou, E. (2018b). "Precise Temporal Disaggregation Preserving Marginals and Correlations (DiPMaC) for Stationary and Nonstationary Processes." Water Resources Research.

Papalexiou, S. M., and Montanari, A. (2019). "Global and Regional Increase of Precipitation Extremes under Global Warming." Water Resources Research.

Paquin, D., Frigon, A., and Kunkel, K.E. (2016). "Evaluation of total precipitable water from CRCM4 using the NVAP-MEaSUREs dataset and ERA-interim reanalysis data, Atmos. Ocean $0,1-8$

Parzybok, Tye W., and Edward M. Tomlinson, "A New System for Analyzing Precipitation from Storms," Hydro Review, 25(3), May 2006, pages 58-65.

Pickands III, J. (1975). "Statistical Inference Using Extreme Order Statistics." The Annals of Statistics, 3(1), 119-131.

Pierce, D.W. (2004). "Beyond the means: validating climate models with higher-order statistics", Computing in Sci. \& Engr., 6(5), 22.

Poon, H.C. and Hwee, H.H. (2010). "Probable maximum precipitation derivation in Malaysia: review and comparison", Internat. J. Hydro-Climatic Engineering, Assoc. Water and EnviroModeling, 37-72.

Prasad, R., Hibler, L.F., Coleman, A.M., and Ward, D.L. (2011). "Design-basis flood estimation for site characterization at nuclear power plants in the United States of America", NUREG/CR-7046, PNNL-20091, Office of Nuclear Regulatory Research, Pacific Northwest National Laboratory, Richland WA 99352.

Prudhomme, C. Reynard, N., and Crooks, S. (2002). "Downscaling of global climate models for flood frequency analysis: where are we now?", Hydrol. Proc., 16, 1137-1150.

Rahman, A., Weinmann, P.E., Hoang, T.M.T., and Laurenson, E.M. (2002). "Monte Carlo simulation of flood frequency curves from rainfall." J. Hydrol. 256, 196-210. 
Rakhecha, P. R. and Soman, M. K. (1994). "Estimation of probable maximum precipitation for a 2-day duration: Part 2- North Indian region." Theoretical and Applied Climatology, SpringerVerlag, 49, 77-84.

Rakhecha, P.R. and Kennedy, M.R. (1985). "A generalized technique for the estimation of probable maximum precipitation in India", J. Hydrol. 78, 345-359.

Rakhecha, P. R., Deshpande, N. R., and Soman, M. K. (1992). "Probable maximum precipitation for a 2-day duration over the Indian Peninsula." Theoretical and Applied Climatology, 45(4), $277-283$.

Rakhecha, P.R. and Soman, M.K. (1994). "Estimation of probable maximum precipitation for a 2day duration: Part 2- North Indian region." Theoretical and Applied Climatology, SpringerVerlag, 49, 77-84.

Rakhecha, P.R. and Clark, C. (1999). "Revised estimates of one-day probable maximum precipitation (PMP) for India", Meteor. Appl., 6, 343-350.

Receanu, R., Hertig, J.A., and Fallot, J.M., (2012). "The estimation of PMP and PMF on Alpine basins in Switzerland", Aerul si Apa: Componente ale Mediului, 2012, p. 212-219.

Reed, D.W. and Stewart, E.J. (1989). "Focus on rainfall growth estimation." Proceedings of the $2^{\text {nd }}$ National Hydrology Symposium, Sheffield, UK, September, British Hydrological Society, 3.57-3.65.

Rezacova, D., Pesice, P., and Sokol, Z. (2005). "An estimation of the probable maximum precipitation for river basins in the Czech Republic", Atmospheric Research, 77, 407-421.

Riedel, J.T. and Schreiner, L.C. (1980). "Comparison of generalized estimates of probable maximum precipitation with greatest observed rainfalls", Tech. Report NWS No. 25, National Weather Service, U.S. Department of Commerce, Silver Spring, Md. 66 p.

Rousseau, A. N., Klein, I. M., Freudiger, D., Gagnon, P., Frigon, A., and Ratté-Fortin, C. (2014a). "Development of a methodology to evaluate probable maximum precipitation (PMP) under changing climate conditions: Application to southern Quebec, Canada." Journal of Hydrology, 519, 3094-3109.

Rouhani H. and Leconte, R. (2016). "A novel method to estimate the maximization ratio of the probable maximum precipitation (PMP) using regional climate model output", Water Resour. Res., 52, 7347-7365.

Salas, J. and Obeysekera, J. (2014). "Revisiting the concepts of return period and risk under nonstationary conditions.” ASCE Journal of Hydrologic Engineering, 19(3). 554-568.

Salas, J.D., Gavilan, G., Salas, F.R., Julien, P.Y., and Abdullah (2014). "Uncertainty of the PMP and PMF”, Chap.28, Hand. Engr. Hydrol., S. Eslamian (Ed), CRC Press, 575-603. 
Salas, J.D. and Salas, F.R. (2016). "Estimating the uncertainty of the PMP", XXVII LatinAmerican Congress of Hydraulics, IAHR, Lima, Peru.

Schaefer, M.G. (1994). "PMP and other extreme storms: concepts and probabilities", In ASDSO National Conference, Baltimore, MD, USA. Pp. 61-73.

Schaefer, M.G. and Barker, B.L., (2005). "Stochastic modeling of extreme floods on the American River at Folsom Dam: flood frequency curve extension", MGS Engineering Consultant for the US Army Corps of Engineers, HEC, Davis, California.

Schreiner, L.C. and Reidel, J.T. (1978). "Probable maximum precipitation estimates", United States East of $105^{\text {th }}$ meridian, Hydrometeorological Report 51, U.S. National Weather Service, Washington D.C.

Serinaldi, F., and Kilsby, C. G. (2014). "Rainfall extremes: Toward reconciliation after the battle of distributions." Water Resources Research, 50(1), 336-352.

Singh, A., Singh, V.P., and Byrd, A.R. (2018a). "Risk analysis of probable maximum precipitation estimates.” Int. J. Hydrol., 2(4), 411-422.

Singh, A., Singh, V.P., and Byrd, A.R. (2018b). "Computation of probable maximum precipitation and its uncertainty.” Int. J. Hydrol., 2(4), 504-514.

Siriwardena, L and Weinmann, P.E. (1998). "A technique to interpolate frequency curves between frequent events and probable maximum events." Cooperative Research Centre for Catchment Hydrology, Monash University, Victoria, Australia, 55 p.

Slade, J. (1936). “An asymmetric probability function.” Transactions of the American Society of Civil Engineers, 62, 35-104.

Smith, J.B., Barker, B.L., and Pernela, L.M. (2010). "Annual Exceedance Probability of Probable Maximum Flood Using a Stochastic Hydrologic Model", Conference Proceedings of the $30^{\text {th }}$ Annual USSD Conference: Collaborative Management of Integrated Watersheds, Sacramento, California. April 12-16, 2010. CD-ROM.

Stedinger, J. R. and Cohn, T. A. (1986). "Flood frequency analysis with historical and paleoflood information." Water Resour. Res., 22(8), 785-793.

Stedinger, J. R., Vogel, R. M., and Foufoula-Georgiou, E. (1993). "Frequency analysis of extreme events." Ch.18 in Handbook of Hydrology (D.R. Maidment, Editor), McGraw Hill, N. York.

Stratz, S. A., and Hossain, F. (2014). "Probable maximum precipitation in a changing climate: Implications for dam design.” Journal of Hydrologic Engineering, 19(12), 06014006.

$\mathrm{Su}, \mathrm{C}$., Chen, X. (2019). "Covariates for nonstationary modeling of extreme precipitation in the Pearl River Basin, China." Atmospheric Research

Svensson, C. and Rakhecha, P. R. (1998). "Estimation of Probable Maximum Precipitation for dams in the Hongru River Catchment, China." Theoretical and Applied Climatology, SpringerVerlag, 59, 79-91. 
Svensson, C. and Jones, D.A. (2010). "Review of rainfall frequency estimation methods." Jour. Flood Risk Manag., 3, 296-313.

Swain, R.E., England, J.F., Bullard, K.L., and Raff, D.A. (2006). "Guidelines for Evaluating Hydrologic Hazards", US Department of the Interior, Bureau of Reclamation, June.

Takara, K. and Loebis, J. (1996). "Frequency analysis introducing Probable Maximum hydrologic events: preliminary studies in Japan and in Indonesia." In: Proceedings of International Symposium on Comparative Research on Hydrology and Water Resources in Southeast Asia and the Pacific, Yogyakarta, Indonesia, 18-22, November 1996, Indonesian National Committee for International Hydrology Programme, 67-76.

Takara, K., and Tosa, K. (1999). "Storm and flood frequency analysis using PMP/PMF estimates." In: Proceedings of International Symposium on Floods and Droughts, Nanjing, China, 18-20 October 1999, 7-17.

Thuy, L. T. T., Kawagoe, S., and Sarukkalige, R. (2019). "Estimation of probable maximum precipitation at three provinces of Northeast Vietnam using historical data and future climate change scenarios", J. Hydrol.: Regional Studies, 23, 1-21.

Tomlinson, E. and W. Kappel, 2009, Dam Safety: Revisiting PMPs, Hydro Review, 28(7).

Toride, K., Cawthorne, D.L., Ishida, K., Kavvas, M.L. and Anderson, M.L., 2018. Long-term trend analysis on total and extreme precipitation over Shasta Dam watershed. The Science of the total environment, 626, pp.244-254.

Towler, E., Rajagopalan, B., Gilleland, E., Summers, R. S., Yates, D., and Katz, R. W. (2010). "Modeling hydrologic and water quality extremes in a changing climate: A statistical approach based on extreme value theory." Water Resources Research, 46(11).

Trenberth, K.E. (2011). "Changes in precipitation with climate change", Clim. Res. 47, 123-138.

USBR, (2015). "II-2 Probabilistic Hydrologic Hazard Analysis", found at Google website, 19 pages.

Veneziano, D., Langousis, A., and Lepore, C. (2009). "New asymptotic and preasymptotic results on rainfall maxima from multifractal theory." Water Resources Research, 45(11).

Veneziano, D., and Yoon, S. (2013). "Rainfall extremes, excesses, and intensity-durationfrequency curves: A unified asymptotic framework and new nonasymptotic results based on multifractal measures." Water Resources Research, 49(7), 4320-4334.

Viglione, A., Castellarin, A., Rogger, M., Merz, R., and Blöschl, G. (2012). "Extreme rainstorms: Comparing regional envelope curves to stochastically generated events." Water Resources Research, 48(1).

Villarini, G., Serinaldi, F., Smith, J. A., and Krajewski, W. F. (2009). "On the stationarity of annual flood peaks in the continental United States during the 20th century." Water Resources Research, 45(8), n/a-n/a. 
Vogel, R. M., Matalas, N. C., England, J. F., and Castellarin, A. (2007). "An assessment of exceedance probabilities of envelope curves.” Water Resources Research, 43(7).

Vogel, R. M., Yaindl, C., and Walter, M. (2011). "Nonstationarity: Flood magnification and recurrence reduction factors in the United States." Journal of the American Water Resources Association, 47(3), 464-474.

von Mises, R. (1936). "La distribution de la plus grande de $\mathrm{n}$ valeurs." Rev. math. Union interbalcanique, 1(1).

Wang, B.H. (1984).. "Estimation of probable maximum precipitation: case studies." ASCE J. Hydrau. Engr., 110(10), 1457-1472.

Wang, G., Li, B., and Wang, J. (2005). "World's greatest known point rainfalls and their enveloping curve formula", Advanc. Water Sci., 17(6), 831-836.

Wangwongwiroj, N., and Khemngoen, C. (2019). "Probable maximum precipitation in tropical zone (Thailand) as estimated by generalized method and statistical method." International Journal of Climatology, 39(13), 4953-4966.

Water Resource Consultants Ltd. (2009). "PROBABLE MAXIMUM FLOOD ESTIMATOR FOR THE CANADIAN PRAIRIES." Agriculture and Agri-Food Canada Prairie Farm Rehabilitation Administration and Environment Branch.

Wilson, P. S., and Toumi, R. (2005). "A fundamental probability distribution for heavy rainfall." Geophysical Research Letters, 32(14), L14812.

WMO (World Meteorological Organization) (1973). "Manual for estimation of probable maximum precipitation." Operational Hydrology Report 1, $1^{\text {st }}$ Edition, Publication 332, Geneva.

WMO (World Meteorological Organization) (1986). "Manual for estimation of probable maximum precipitation." Operational Hydrology Report 1, $2^{\text {nd }}$ Edition, Publication 332, Geneva.

WMO (World Meteorological Organization) (2009). "Manual on Estimation of Probable Maximum Precipitation (PMP)", WMO-No. 1045, 259 pages.

Yilmaz, A., Imteaz, M., and Perera, B. (2017). "Investigation of non-stationarity of extreme rainfalls and spatial variability of rainfall intensity-frequency-duration relationships: a case study of Victoria, Australia." International Journal of Climatology, 37(1), 430-442. 